(Aus dem physiologischen Laboratorium in Bonn.)

\title{
Ueber den Maximalwerth des Gesammtglykogengehalts von Hunden.
}

\author{
Von
}

\section{Bernhard Sehöndortr.}

Für die richtige Beurtheilung gewisser Fragen des Kohlehydratstoffwechsels ist die Kenntniss von dem Gesammtglykogengehalt eines Thieres und eines möglicben Maximalwerthes desselben eine nothwendige Voraussetzung. Für die richtige Entscheidung der Frage z. B., woher beim Phloridzindiabetes der ausgeschiedene Zucker bei hungernden Hunden stammt, ist es nothwendig zu wissen, wieviel Glykogen der Hund vor der Einnahme des Phloridzins in seinen Organen enthalten haben kann.

„Hiertritt dann nun, wie Pflüger ${ }^{1}$ ) es in seiner zusammenfassenden Arbeit über das Glykogen ausspricht, gleich die erstaunliche Thatsache auf, dass keine Versuche vorliegen, welcheeine Grundlagegebenzur Beurtheilung, wieviel Glykogen in dem Körper eines reichlich ernährten Hundes vorhanden sein kann."

Aus diesen Gründen hat v. Mering sich bei seinen Versuchen über den Phloridzindiabetes auf Versuche von Böhm und $\mathrm{Hoff}$ mann ${ }^{2}$ ) bezogen, welche den Gesammtglykogengehalt im Körper der Katze bestimmten. Böhm und Hoffmann fütterten ausgewachsene Katzen mit rohem Fleisch ungefähr 8-10 Tage lang und bestimmten dann in Blut, Leber und Muskeln das Glykogen nach der Brücke'schen Methode durch Auskochen mit Wasser. In den übrigen Organen wurde das Glykogen nicht bestimmt.

"Wir überzeugten uns durch mehrere Versuche, dass in den übrigen Körperorganen, d. h. Central-

1) Pflüger's Archiv Bd. 96 S. 268. Im Original nicht gesperrt gedruckt.

2) Archiv f. exper. Pathol. u. Pharmak. Bd. 8 S. 289.

E. Pflügex, Archiv für Physiologie. Bd. 99. 
nervensystem, Milz, Magen- und Darmeanal für gewöhnlich keine wägbaren Mengen von Kohlehydraten enthalten sind."

Sie fanden bei ihren Versuchen als Gesammtglykogengehalt der Katze in Zucker ausgedrückt pro Kilo Katze 1,5-8,5 g Glykogen. v. Mering rechnet desshalb als Maximalwerth pro Kilo Hund 8,5 g Glykogen.

Nun ist dieser Maximalwerth entschieden zu klein, denn in den übrigen Körperorganen können noch ganz beträchtliche Mengen von Glykogen enthalten sein. So fand z. B. Pflü ger ${ }^{1}$ ) bei der Untersuchung des Glykogengehaltes eines Hundes, der 28 Tage gehungert hatte, dass in den Knochen und Knorpeln noch ca. 1/9 der Gesammtmenge des ganzen Körperglykogens enthalten war oder absolut $5,898 \mathrm{~g}$ und im Fell noch 1,402 $\mathrm{g}$ Glykogen; desshalb ist es wohl als sicher anzunehmen, dass in den Organen bei Thieren, die gefüttert sind, nicht zu vernachlässigende Glykogenmengen vorkommen.

Ausserdem bestimmten die beiden Forscher das Glykogen durch

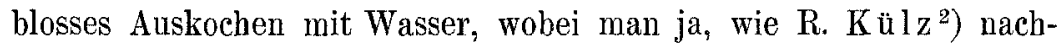
gewiesen hat, nur ungefähr $3 / 4$ des vorhandenen Glykogens erhält.

Aus diesen Gründen ist ein Maximalwerth von $8,5 \mathrm{~g}$ Glykogen pro Kilo Hund entschieden als zu klein zu betrachten.

Bei Fröschen fand Pflüger $\mathrm{r}^{8}$ ) im Monat März nach dem Winterschlaf noch $10 \mathrm{~g}$ Glykogen auf 1 Kilo Thier.

Um nun einen Anhaltspunkt für den Maximalwerth des Gesammtglykogens zu haben, berechnete Pflüger aus dem Glykogengehalt des Pferdemuskels, der gewöhnlich $2 \%$ und noch mehr Glykogen enthält, und der Annahme von $40 \%$ Fleischgewicht, dass auf $1 \mathrm{~kg}$ Thier $8 \mathrm{~g}$ Glykogen in den Muskeln kämen. Wenn man nun annähme, dass bei gutem Ernährungszustande die Leber ebensoviel Glykogen als die Muskeln enthielte, so würden beim Pferde als Glykogengehalt für Leber und Muskeln $16 \mathrm{~g}$ Glykogen pro Kilogramm Thier zu rechnen sein. Ebenso rechnete er für den Hund aus den Versuchen von $\mathrm{Pavy}^{4}$ ) den möglichen Maximalwerth des Glykogengehaltes des ganzen Thieres aus. Pavy bestimmte,

1) Pflüger's Archiv Bd. 71 S. 319.

2) Zeitschr. f. Biologie Bd. 22 S. 194.

3) Pflüger's Archiv Bd. 71 S. 319.

4) F. W. Pary, The Physiology of the Carbohydrates p. 114. London 1894. 
dass bei gemischter, an Kohlehydrat reicher Nahrung ein Hund bis $\mathrm{zu} 12 \%$ Glykogen, durch Inversion in Zucker festgestellt, in der Leber enthält, und dass die Leber dann $6,6 \%$ des Körpergewichts ausmacht. Daraus folgt, dass $1 \mathrm{~kg}$ Hund $7,92 \mathrm{~g}$ Leberglykogen enthält. Weil nun im Körper wohlgenährter Hunde mindestens ebensoviel Glykogen als in der Leber sich befindet, würde sich als Gesammtglykogen pro Kilogramm Thier $15,8 \mathrm{~g}$ Glykogen berechnen.

Ein weiterer Versuch, das Gesammtglykogen eines Thieres zu bestimmen, ist von Erwin Voit') ausgeführt worden. Derselbe fütterte eine Gans von $2 \mathrm{~kg}$ Gewicht nach einer $4^{1 / 2}$ tägigen Hungerperiode 5 Tage lang mit Reisnudeln: im Ganzen wurden 766,2 $\mathrm{g}$ trockener Reis verfüttert. Nach Beendigung des Versuches wurde das Thier getöltet und das Glykogen in der Leber und den Muskeln bestimmt. Die Glykogenbestimmungen wurden nach der Brükeschen Methode, ausgeführt, und die Zahlen beziehen sich auf aschefreies Glykogen. Das Glykogen in den übrigen Organen wurde nicht bestimmt, sondern für die Eingeweide, unter welcher Bezeichnung der Darmtractus mit den zugehörigen Drüsen, das Gehirn und das Rückenmark und der Geschlechts- und Harnapparat zusammengefasst ist, aber ohne Haut, Knochen und Fettgewebe, wurde der Procentgehalt der Muskeln der Berechnung zu Grunde gelegt.

Seine Versuche ergaben folgende Zahlen:

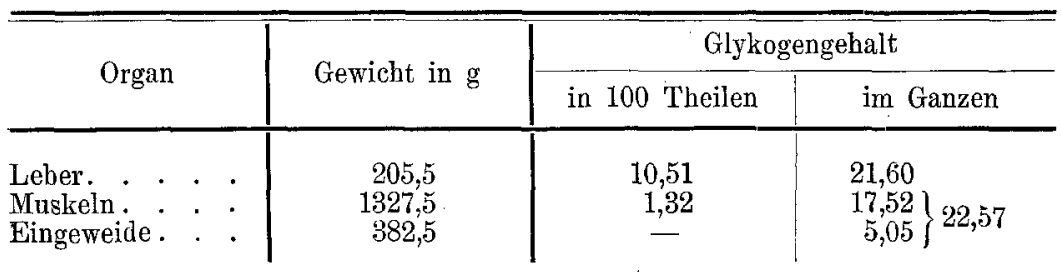

Je nachdem er den Glykogengehalt des gesammten Körpers aus der Glykogenmenge der Muskeln und der Leber allein oder mit den Eingeweiden berechnete, erhielt er 39,19 resp. 44,17 g Glykogen, wobei aber immer noch der Glykogengehalt der Haut, der Knochen und des Fettgewebes vernachlässigt wurde.

Er fand also:

Pro Kilo Thier 19,56 resp. 22,08 g Glykogen.

Für den Hund, an dem Untersuchungen über den Kohlehydrat-

1) Zeitschr. f. Biologie Bd. 25 S. 546. 
stoffwechsel in so vielen Fällen angestellt worden sind, liegt also kein Versuch vor, aus dem mit Sicherheit hervorgeht, wie hoch in maximo bei reichlicher Ernährung der Gesammtglykogengehalt aller Organe steigen kann. Da aber ja die Kenntniss dieser Thatsache für die Beurtheilung vieler Fragen unbedingt nothwendig erschien, so folgte ich gerne einer Aufforderung von Herrn Prof. Pflüger, den Maximalwerth für den Gesammtglykogengehalt gut genährter Hunde festzustellen.

Zunächst stand es als nothwendig fest, uns nicht nur mit der Glykogenbestimmung in der Leber und der Muskulatur zu begnügen, sondern, da es sich herausgestellt hatte, dass auch in den übrigen Organen nicht unbeträchtliche Mengen von Glykogen vorkommen könnten, auch in allen anderen Organen die Glykogenmenge festzustellen.

Es wurde also in allen Versuchen das Glykogen bestimmt in der Leber, den Muskeln, den Knochen, den Eingeweiden, worunter sämmtliche inneren Organe mit Ausnahme von Herz und Gehirn und Leber zu verstehen sind, dem Fell, dem Herzen, dem Gehirn und dem Blut. Nur in vier Versuchen wurde der Glykogengehalt des Blutes nicht festgestellt, weil sich der Glykogengehalt des Blutes als so gering erwies, dass er bei der Berechnung der Glykogenmengen des ganzen Thieres kaum in Betracht kam.

Bezüglich der Glykogenanalyse der Muskeln und Knochen ist zu bemerken, dass wir nicht die ganze Muskulatur und die ganzen Knochen auf Glykogen untersuchten, sondern das Thier genau in der Medianebene durchsägten und nur das Glykogen der einen Hälfte bestimmten. Zu diesen Verfahren, welche uns die Vorbereitung von Muskeln und Knochen zur Analyse sehr erleichterte und es uns ermöglichte, sehr rasch diese Organe auf Glykogen zu verarbeiten, so dass eine bedeutende Verringerung des Glykogengehaltes dureh Fermentwirkung nicht zu erwarten war, hielten wir uns für berechtigt, weil die Versuche von $\mathrm{Cramer}^{1}$ ) ergeben haben, dass wenigstens bei grösseren Thieren der Glykogengehalt der Muskeln der beiden Hälften ungefähr der gleiche ist. Die Theilung des Thieres in zwei Hälften, die wir von einem Metzger ausführen liessen, war bezüglich des Gewichtes so genau getroffen, dass die beiden Hälften ungefähr das gleiche Gewicht hatten. Man konnte

1) Zeitschr. f. Biologie Bd. 24 S. 70. 
desshalb, ohne einen grösseren Fehler zu begehen, den Glykogengehalt von Muskeln und Knochen des ganzen Hundes aus dem Glykogengehalt der Muskeln und Knochen des halben Hundes durch Multiplication mit 2 berechnen.

Bei der Fütterung der Hunde gingen wir von der Erwägung aus, dass ein möglichst grosser Glykogenansatz wahrscheinlich dann stattfinden würde, wenn neben Kohlehydraten eine grössere Menge Eiweiss in der Nahrung sei, so dass vom Eiweiss der grössere Theil des Stoffwechsels bestritten und das aufgenommene Kohlehydrat als Glykogen angesetzt würde.

Es wurden desshalb die Hunde mit Fleisch und Reis gefüttert. Da sich aber bei den beiden ersten Versuchen herausstellte, dass die Reisstärke, wenigstens bei Hunden, nicht sebr geeignet sei, eine Glykogenanhäufung herbeizuführen, so wurden in den folgenden Versuchen, um die Kohlehydratmenge in der Nahrung auch noch zu erhöhen, neben Fleisch und Reis noch Kartoffeln und eine grössere Menge Rohrzucker verfüttert und zwar bei Hunden von einem Gewicht von $6-9 \mathrm{~kg}$ anfangs 100 , dann bis $150-200 \mathrm{~g}$ Rohrzucker pro Tag.

Die Ausführung der Glykogenanalyse geschah nach den von Pflüg er ${ }^{1}$ ) angegebenen Vorschriften zur Ausführung einer quantitativen Glykogenanalyse.

Es wurden $100 \mathrm{~g}$ Organbrei in $100 \mathrm{ccm} 60 \%$ ige siedende Kalilauge gebracht, zwei Stunden lang im Wasserbarde erhitzt, in ein 400 ccm-Kölbchen entleert, auf $400 \mathrm{ccm}$ aufgefüllt; die Lösung durch Glaswolle filtrirt. Ein aliquoter Theil dieser Flüssigkeit wird mit dem gleichen Volumen Alkohol von $96 \%$ Tr. versetzt, das gefällte Glykogen am nächsten Tage durch ein schwedisches Filter abfiltrirt, mit einer Lösung, welche enthält

$$
\begin{aligned}
& 1 \text { Vol. Kalilauge von } 15 \% \\
& 2 \% \text { Alkohol " } 96 \% \mathrm{Tr} \text {, }
\end{aligned}
$$

zwei Mal gewaschen, dann zwei Mal mit Alkohol von $96 \%$ Tr. Das Glykogen wird dann in Wasser gelöst, in einen geaichten Kolben gebracht und pro $100 \mathrm{ccm}$ Lösung $5 \mathrm{ccm}$ Salzsäure von 1,19 spec. Gew. zugefügt, so dass die Lösung ungefähr 2,2\% $\mathrm{HCl}$ enthält. Diese Lösung wird drei Stunden lang im siedenden Wasserbade erhitzt, nach dem Abkühlen des Kölbchens mit Wasser

1) Pflüger's Archiv Bd. 96 S. $94-104$. 
bis zur Marke aufgefüllt, durch ein trockenes schwedisches Filter filtrirt und in dieser Lösung der Zucker gravimetrisch bestimmt und aus der gefundenen Kupferoxydulmenge der Zucker- resp. Glykogengehalt des Organs berechnet.

Nun ergaben die Fütterungsversuche mit Rohrzucker solche riesenhafte Werthe für den Glykogengehalt der Organe, dass uns die Höhe derselben fast unglaublich erschien und wir es für möglich hielten, dass das erhaltene Kupferoxydul vielleicht durch Beimischungen, die dann als Kupferoxydul gewogen wurden, verunreinigt wäre, zumal da bei den fünf letzten Versuchen nicht das Merck'sche Kaliumbydrat I $a$ angewandt wurde, sondern das Kahlbaum'sche mit Alkohol gereinigte Kaliumhydrat. Damit nun unsere Ergebnisse nicht als durch "Versuchsfehler" bedingte bezeichnet werden, hielten wir es für unerlässlich, den Kupferoxydulwerth zu controliren, und es wurde desshalb bei den fünf letzten Versuchen das Kupfer nach Volhard titrirt und daraus der Zucker berechnet.

Auf solche Weise wurde in der Leber und in den Muskeln das Glykogen bestimmt. Bei den übrigen Organen, bei welchen eine geringere Glykogenmenge zu erwarten war, wurden, um eine möglichst grosse Genauigkeit der Analyse zu erzielen, grössere Mengen Organe in Arbeit genommen. Bei den kleineren Hunden wurden Knochen, Fell und Eingeweide und Blut ganz in Kalilauge gelöst und ein aliquoter Theil zur Analyse benutzt, bei den grossen Hunden eine entsprechende grosse Organmenge.

Falls bei der Lösung des Glykogens auf dem Filter ein grösserer Rückstand übrig blieb, oder die Glykogenmenge auf dem Filter. sehr gross war, so wurde das Filter so lange mit Wasser ausgekocht, bis eine kleine Menge Filtrat keine Trübung mehr mit Alkohol gab.

Eine Ausnahme von dieser gewöhnlichen Art des Verfahrens geschah beim Gehirn und bei den Knochen.

Wenn man das Gehirn in Kalilauge löst und die alkalische Lösung mit einem gleichen Volumen Alkohol fällt, so entsteht ein ganz bedeutender Niederschlag, so dass es den Anschein hat, als enthielte das Gehirn viel Glykogen. Wenn man dann versucht, diesen Niederschlag auf dem Filter zu lösen, so zeigt sich, dass der grösste Theil dieses Niederschlags im Wasser unlöslich ist. Die Filtration dauert sehr lange, und auch durch Auskochen mit Wasser gelingt es nicht, das Glykogen aus diesem Niederschlag in Lösung zu bringen. Es wurde desshalb mit Ausnahme von Versuch I in allen übrigen 
Versuchen der Niederschlag direct in das zur Invertirung gebrauchte Kölbchen gebracht und das Glykogen auf diese Weise invertirt. Es ergab sich, dass auf diese Weise viel mehr Zucker erhalten wurde, als wenn man das Glykogen auf dem Filter löste.

Die Knochen wurden mit dem Hackbeil etwas zerkleinert und in einer Porzellanschale auf offener Flamme mit dem gleichen Volumen $30 \%$ iger Kalilauge so lange gekocht, bis die Knochen so weich geworden waren, dass sie sich in einer Schale zu einem Brei zerstampfen liessen, was in verhältnissmässig kurzer Zeit eintrat. Dann wurde die Flüssigkeit abgegossen, die zerstampfte Knochenmasse nochmals mit einer kleineren Menge $30 \%$ iger KOH-Lauge gekocht, die Flüssigkeit zu der bisherigen Flüssigkeit zugegossen; der Knochenrückstand wurde dann nochmals mehrere Male mit kaltem Wasser verrieben und die abgegossene Flüssigkeit durch Glaswolle filtrirt. Alle Flüssigkeiten wurden vereinigt und die Knochenlösung auf $15 \% \mathrm{KOH}$ verdünnt.

Enthielt die Knnochenlösung sehr viel Fett, so liess man in grossen Standeylindern resp. geaichten cylindrischen Scheidetrichtern das Fett sich absetzen und zog das Volumen der oben abgeschiedenen Fettmenge vom Volumen der Knochenlösung ab. Ein aliquoter Theil dieser Knochenlösung wurde dann zur Analyse benutzt.

Die Ausführung der Versuche, um die Organe auf Glykogen zu verarbeiten, geschah so schnell wie möglich, um eine grössere Umwandlung des Glykogens in Zucker, so weit es eben ging, zu verhindern.

Bei der Tödtung des Thieres hielten wir es für zweckmässig, dass starke Zuckungen möglichst vermieden wurden, da es nach den Versuchen von E. K ül $z^{1}$ ) und Anderen feststeht, dass starke Muskelbewegungen das Glykogen bedeutend vermindern können.

Es warden desshalb die kleinen Hunde durch den Genickstich getödtet und dann durch einen Stich in die Carotis verbluten gelassen. Der grosse Hund von $60 \mathrm{~kg}$ wurde vermittelst eines Schiessapparates, wie er im hiesigen Schlachtbause zur Tödtung der Ochsen benutzt wird, durch einen Schuss in's Grosshirn betäubt und dann durch einen Carotisstich das Blut erhalten. In beiden Fällen wurden die Krämpfe vermieđen. Das Blut wurde direct in Kalilauge aufgefangen. Sofort nach dem Verbluten wurde die Bauchhöhle ge-

1) Festschrift zu K. Ludwig's Doctor-Jubiläum. Marburg 1891. 
offnet, die Leber herausgenommen, gewogen, in der Mühle gemahlen und in siedende Kalilauge gebracht. In der Zwischenzeit wurde das Fell abgezogen, der Hund in der Medianebene durchgesägt, die Muskeln schnell abpräparirt, zerkleinert und ebenfalls in siedende Kalilauge gebracht. Dann wurden Knochen, Fell, Eingeweide, nachdem sie von den noch darin befindlichen Speiseresten gereinigt und in der Mühle gemahlen waren, Herz und Gehirn ebenfalls mit der grössten Schnelligkeit verarbeitet.

Gewöhlich waren eine halbe bis dreiviertel Stunde nach dem Tode des Thieres alle Organe in siedender Kalilauge und dem Einfluss der Fermentwirkung entzogen.

Bevor ich nun zur Besprechung der einzelnen Versuche und ihrer Ergebnisse übergehe, die ich zunächst in Form von Tabellen mittheilen will, indem ich zum Schluss die genaueren analytischen Belege gebe, möchte ich bemerken, dass in allen Fällen bei den Zuckerbestimmungen Doppelanalysen ausgeführt wurden, die gut überein stimmten. Es wurde aber nicht das Mittel aus dem erbaltenen Kupferoxydulwerth genommen und daraus der Zucker berechnet, sondern es wurde der grössere Werth als der richtigere angenommen und daraus der Zucker berechnet, weil der kleinere dadurch bedingt ist, dass Spuren von Kupferoxydul durch das Asbestfilter durchgegangen sind. Die Unterschiede betrugen aber stets nur wenige Milligramme. Ferner werden in den Tabellen sowohl die aus Kupferoxydul berechneten Zuckerwerthe als die daraus durch Multiplication mit 0,927 erhaltenen Glykogenwerthe angegeben. Denn es haben zwar die Versuche von Nerking ${ }^{\prime}$ ) ergeben, dass man bei der Inversion des Glykogens mit 2,2\% Salzsäure in 3 Stunden nie den theoretischen Werth, sondern nur $97 \%$ der theoretischen Menge Zucker erhält, und dass unan das Gewicht des durch Inversion erbaltenen Zuckers mit 0,927 multipliciren muss, um den richtigen Werth für das Glykogen zu finden. Aber diese Thatsache ist noch nicht mit hinreichender Sicherheit festgestellt, denn auch Nerking's Glykogen enthielt noch $0,026 \%$ Stickstoff, und es wäre doch möglich, dass die beobachtete Abweichung vom theoretischen Werth bei der Inversion durch eine solche Verunreinigung bedingt sein könne und nicht durch Reversion, wie man bis jetzt annimmt.

1) Pflüger's Archiv Bd. 85 S. 324. 


\section{Versuch I.}

Ein Hund von $10 \mathrm{~kg}$ wird 16 Tage lang mit anfangs $500 \mathrm{~g}$, dann $700 \mathrm{~g}$ Fleisch und $100 \mathrm{~g}$ resp. $150 \mathrm{~g}$ Reis gefüttert und auf die oben angegebene Weise die Glykogenuntersuchung ausgeführt.

(Siehe Tabelle I auf S. 200.)

Das Gewicht des darmreinen Hundes beträgt $12000 \mathrm{~g}$. Der Zuckergehalt sämmtlicher Organe beträgt $\mathbf{7 4 , 7 8} \mathrm{g}$ Der Glykogengehalt . . . . . . . . $69,34 \mathrm{~g}$ $1 \mathrm{~kg}$ Thier enthält also . . . . . . . 6,232 g Zucker, resp. $5,778 \mathrm{~g}$ Glykogen.

In der Leber sind $15,02 \mathrm{~g}$ Zucker, in den übrigen Organen $59,75 \mathrm{~g}$, also sind in allen Organen zusammen 3,98 Mal so viel Zucker resp. Glykogen als in der Leber.

Das Lebergewicht beträgt 2,67\% vom Körpergewicht.

\section{Versuch II.}

Weil eine Reihe von Versuchen äber Phloridzindiabetes, z. B. die Versuche von Hartogh und Schumm ${ }^{1}$ ) unter Rumpf's Leitung, an sehr grossen Hunden, z. B. einer Dogge von $60 \mathrm{~kg}$ Gewicht, ausgeführt wurden, so versuchten wir, uus einen Hund von derartigem Gewicht zu verschaffen, um in demselben, nach Fütterung mit Fleisch und Reis, den Gesammtglykogengehalt zu bestimmen.

Es gelang uns, einen Hund von $53 \mathrm{~kg}$ Gewicht zu erhalten; derselbe wird, um ihn durch Fleischmast auf ein Gewicht von $60 \mathrm{~kg}$ $\mathrm{zu}$ bringen, 14 Tage lang mit $4000 \mathrm{~g}$ magerem Pferdefleisch pro Tag gefüttert. Sein Gewicht stieg auf $58 \mathrm{~kg}$; dann erhält er 4 Tage lang $3000 \mathrm{~g}$ Fleisch und $300 \mathrm{~g}$ Reis, dann 5 Tage lang $2500 \mathrm{~g}$ Fleisch und $400 \mathrm{~g}$ Reis. Bezüglich der Glykogenanalyse ist zu bemerken, dass wir bei der Glykogenbestimmung in der Leber zunächst die Glykogenbestimmung in der gewöhnlichen Weise ausführten. Eine zweite Portion Leber wurde, weil wir an die Möglichkeit dachten, dass eine sehr schnelle Umwandlung von Glykogen in Zucker vor sich ginge und dieser Zucker dann der Analyse entging, zunächst mehrmals mit Wasser ausgekocht, der Wasserauszug auf ein bestimmtes Volumen gebracht und direct mit Salzsäure invertirt. Der Rückstand wurde in Kalilauge gelöst und auf gewöhn- 


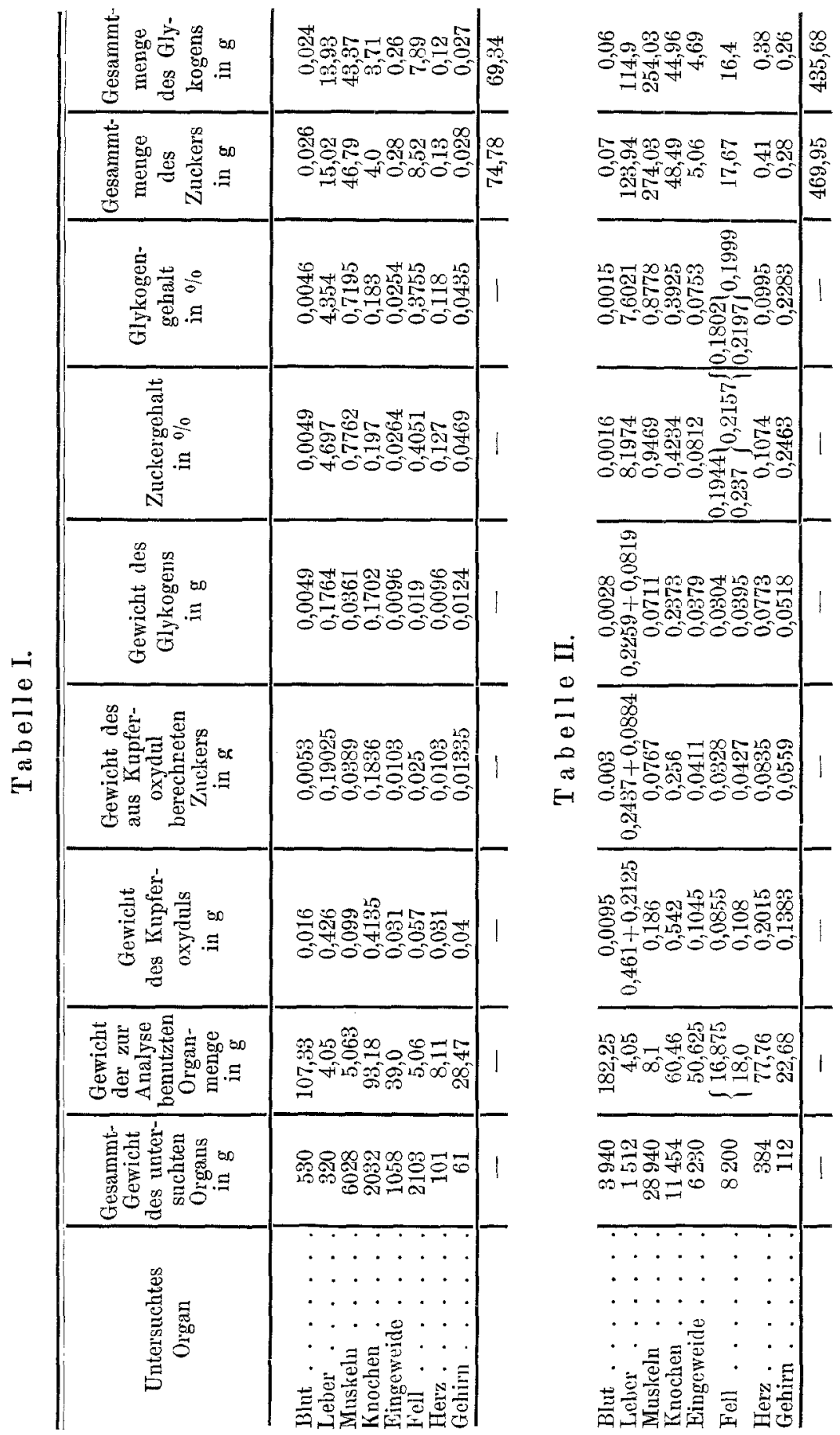


liche Weise auf Glykogen untersucht. Da auf diese Weise ein höherer Werth für den Glykogengehalt der Leber erzielt wurde, so ist in der Tabelle nur dieser Werth angegeben.

Das Gewicht des Hundes am Morgen des Versuchstages beträgt 63250 g. Der Darminhalt betrug $2592 \mathrm{~g}$, also wiegt das dạrmreine Thier $60658 \mathrm{~g}$.

Der Hund wird durch einen Schuss in's Grosshirn getödtet und die Glykogenbestimmung ergab folgende Werthe:

(Siehe Tabelle II auf S. 200.)

Der Zuckergehalt sämmtlicher Organe beträgt $469,95 \mathrm{~g}$

"Glykogengehalt " " " 435,68 "

$1 \mathrm{~kg}$ Thier enthält also 7,7465 g Zucker, resp.

\section{7,182 "Glykogen.}

In der Leber sind $123,94 \mathrm{~g}$ Zucker, in den übrigen Organen $346,01 \mathrm{~g}$. Also sind in allen Organen zusammen 2,79 Mal so viel Zucker resp. Glykogen als in der Leber. Das Lebergewicht beträgt 2,49\% vom Körpergewicht.

Die bisherigen Versuche hatten ergeben, dass durch die Fütterung mit Fleisch und Reis ein Maximalwerth für den Glykogengehalt der Hunde nicht erzielt wurde, vielmehr die erhaltenen Werthe noch unter den bisherigen beobachteten Werthen lagen; desshalb wurde versucht, ob es nicht möglich sei, durch eine andere Art der Fütterung und durch eine andere Vorbereitung der Hunde für den eigentlichen Versuch höhere Werthe für den Glykogengehalt zu erlangen.

Von der Erwägung ausgehend, dass vielleicht eine längere Hungerperiode vor dem eigentlichen Fütterungsversuch einen stärkeren Glykogenansatz herbeiführen könne, indem auch bei E'rwin Voit in seinem Versuche an der Gans, bei welcher er den Werth von 22 g Glykogen pro Kilo erhielt, dieselbe $4^{1 / 2}$ Tage hungerte, liessen wir in den folgenden Versuchen die Hunde acht Tage vor der eigentlichen Fütterung hungern. Dann wurde die Nahrung in der Art verändert, dass wir ausser Fleisch und Reis den Thieren noch Kartoffeln und Rohrzucker gaben. Es wurden zu dem Versuche sechs Hunde benutzt.

Das Gewicht der Hunde nach achttägigem Hungern betrug:

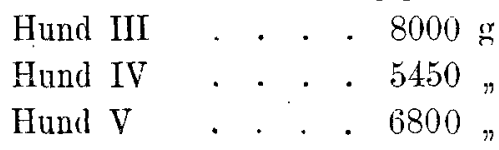




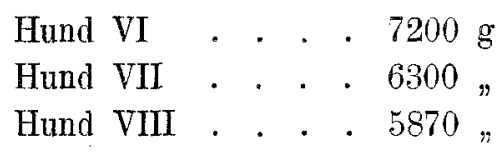

Die Hunde wurden acht Tage gefuttert und erhielten die ersten drei Tage

$$
\begin{aligned}
& 200 \mathrm{~g} \text { Fleiseh } \\
& 100 \text { "Reis } \\
& 100 \text { "Kartoffeln. }
\end{aligned}
$$

Die beiden nächsten Tage erhielten sie eine Zulage von $100 \mathrm{~g}$ Schwarzbrod und $50 \mathrm{~g}$ Kartoffeln. Da sie das Brod aber schlecht vertrugen, indem bei einigen Diarrhöe auftrat, wurde dasselbe wieder weggelassen und dafür 150-200 $\mathrm{g}$ Rohrzucker pro Tag der Nahrung zugefügt. Am Abend vor der Tödtung erhielten sie noch einen Theil

\begin{tabular}{|c|c|c|}
\hline Hund & III & $1507 g$ \\
\hline " & IV & 1782 \\
\hline & V & 2018 \\
\hline & $\mathrm{VI}$ & 809 \\
\hline & VII & 115 \\
\hline & VII & 930 \\
\hline
\end{tabular}
desselben Futters mit Rohrzucker. Die Gewichtszunahme bei den einzelnen Hunden während dieser Fütterung betrug:

Von Hund III-VII wurde der Gesammtglykogengehalt bestimmt. Von Hund VIII, den Herr cand. med. H. Löschke zu anderen Zwecken benutzte, wurde nur der Glykogengehalt der Leber bestimmt. Herr Löschke war so liebenswürdig mir zu gestatten, den von ihm gefundenen Glykogenwerth der Leber auch für meine Zwecke zu benutzen, wofür ich ihm auch an dieser Stelle meinen besten Dank ausspreche.

Bezüglich der Analyse des Glykogens ist zu bemerken, dass wegen der Kostspieligkeit des Versuches bei diesen sechs Hunden nicht das Kaliumhydrat Merck Ia benutzt wurde, sondern das Kahlbaum'sche Kaliumhydrat mit Alkohol gereinigt.

Da nun die Möglichkeit vorhanden war, dass bei der Anwendung des Kahlbaum'schen Präparates die abnorm hohen Werthe für den Glykogengehalt, die wir erhielten, durch Verunreinigung des Kupferoxyduls bedingt waren, so wurde in allen folgenden Versuchen das Kupfer, welches in dem gewogenen Kupferoxydul enthalten war, durch 'Titration nach $\mathrm{Volh}$ a $\mathrm{rd}$ bestimmt und aus der so erhaltenen Kupfermenge der Zucker- resp. Glykogengehalt berechnet. 


\section{Versuch III.}

Ein kleiner brauner Pudel wurde also auf die angegebene Art, nachdem er acht Tage gehungert hatte, gefütert und durch den Nackenstich getödtet. Der Hund nahm während der Fütterung um 1507 g an Gewicht zu.

Das Gewicht des darmreinen Thieres betrug vor der Tödtung 9507 g. Die Glykogenbestimmung ergab folgende. Werthe:

(Siehe Tabelle III auf S. 204.

Der Glykogengehalt sämmtlicher Organe beträgt also : als Zucker gerechnet . . . . . $308,89 \mathrm{~g}$ der Glykogengehalt . . . . . 285,91 "

$1 \mathrm{~kg}$ Thier enthält also, da das darmreine Thier $9507 \mathrm{~g}$ wiegt, 32,49 g Zucker, resp.

30,07 "Glykogen.

Das Lebergewicht macht $8,6 \%$ vom Körpergewicht aus.

In der Leber sind $165,21 \mathrm{~g}$ Zucker, in den übrigen Organen zusammen $143,68 \mathrm{~g}$. Es kommen also auf $100 \mathrm{~g}$ Zucker resp. Glykogen in der Leber $86,96 \mathrm{~g}$ Zucker in den übrigen Organen.

Wie aus der folgenden Tabelle IV ersichtlich ist, hat die Titration des Kupfers nach Volhard ergeben, dass von einer grösseren Verunreinigung des Kupferoxyduls nicht die Rede sein kann. Die beobachteten Unterschiede sind so klein, dass sie für derartige Versuche nicht in Betracht kommen.

T a b e 11 e IV.

\begin{tabular}{|c|c|c|c|c|c|c|}
\hline \multirow{2}{*}{\multicolumn{3}{|c|}{ Organ }} & \multicolumn{2}{|c|}{ Zucker, berechnet in $\mathrm{mg}$} & \multirow{2}{*}{$\begin{array}{c}\text { Differenz } \\
\text { absolut }\end{array}$} & \multirow{2}{*}{$\begin{array}{c}\text { Differenz } \\
\text { in } \%\end{array}$} \\
\hline & & & aus $\mathrm{Cu}_{2} \mathrm{O}$ & aus $\mathrm{Cu}$ & & \\
\hline $\begin{array}{l}\text { Leber a } \\
\text { Leber b } \\
\text { Muskel . } \\
\text { Knochen } \\
\text { Eingeweide } \\
\text { Fell . . } \\
\text { Herz . } \\
\text { Gehirn . }\end{array}$ & & $\begin{array}{l}\dot{ } \\
\dot{5} \\
\dot{5} \\
\dot{.}\end{array}$ & $\begin{array}{c}208,6 \\
203,2 \\
56 \\
159,1 \\
138,4 \\
100,5 \\
119,3 \\
-\end{array}$ & $\begin{array}{c}205,3 \\
201,3 \\
55,5 \\
155 \\
132 \\
94,7 \\
118,2 \\
-\end{array}$ & $\begin{array}{r}-3,3 \\
-1,9 \\
-0,5 \\
-4,1 \\
-1,4 \\
-5,8 \\
-1,1 \\
-\end{array}$ & $\begin{array}{l}-1,6 \\
-0,9 \\
-0,89 \\
-2,6 \\
-1,04 \\
-5,8 \\
-0,92 \\
-\end{array}$ \\
\hline
\end{tabular}

Die Uebereinstimmung der Cu-Bestimmung mit der $\mathrm{Cu}_{2} \mathrm{O}$-Bestimmung lässt es ferner auch unbedenklich erscheinen, für derartige Versuche das gewöhn- 


\begin{tabular}{|c|c|c|c|c|}
\hline 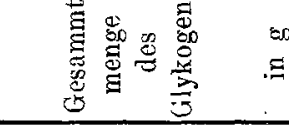 & 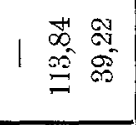 & $\begin{array}{l}5 \\
65 \\
05 \\
10\end{array}$ & 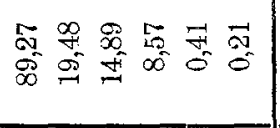 & 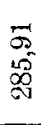 \\
\hline 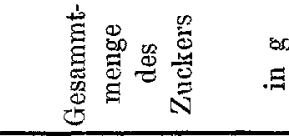 & 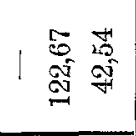 & 20 & 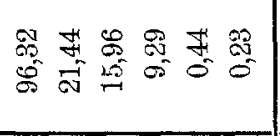 & 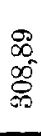 \\
\hline 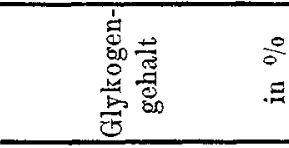 & $\mid \begin{array}{ll}\infty & \infty \\
\infty & 0 \\
\infty & 0 \\
\infty & \infty \\
=\end{array}$ & 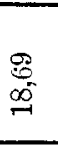 & 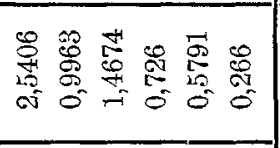 & 1 \\
\hline 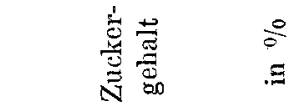 & 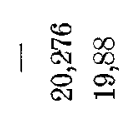 & 点 & 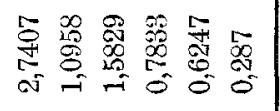 & 1 \\
\hline 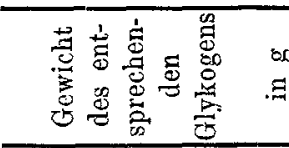 & 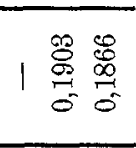 & 1 & 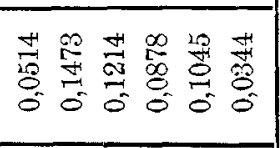 & 1 \\
\hline 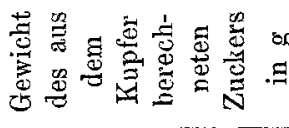 & 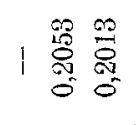 & & 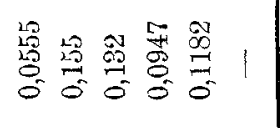 & 1 \\
\hline 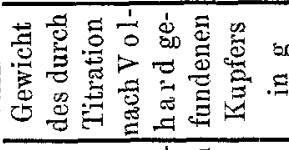 & 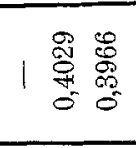 & 1 & 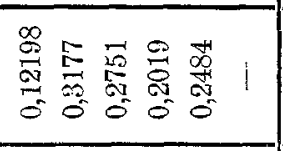 & $!$ \\
\hline 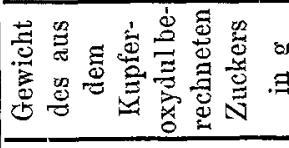 & 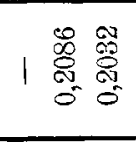 & 1 & 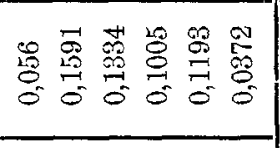 & 1 \\
\hline 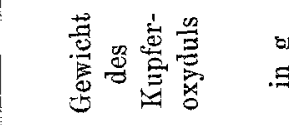 & 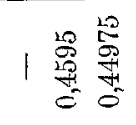 & 1 & 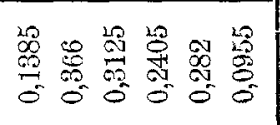 & 1 \\
\hline 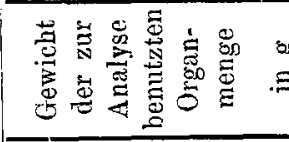 & 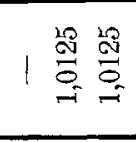 & & 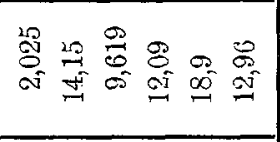 & 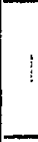 \\
\hline 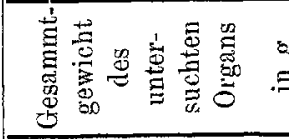 & 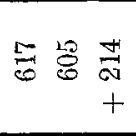 & $\frac{\rho}{\infty}$ & 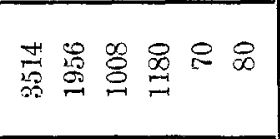 & 1 \\
\hline 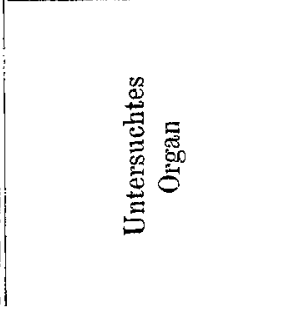 & 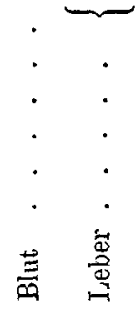 & & 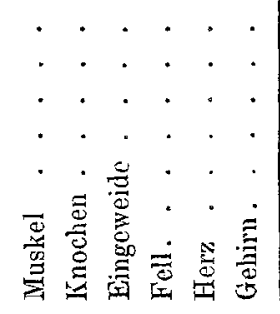 & \\
\hline
\end{tabular}


Ueber den Maximalwerth des Gesammtglykogengehalts von Hunden. 205

liche Kahlbaum'sche, mit Alkohol gereinigte Kaliumhydrat zu benutzen. Man muss nur, wie es auch bei unseren Versuchen geschehen ist, für die Auswaschung des Glykogens auf dem Filter das Kaliumhydrat Merck Ia a nwenden. Wegen der Kostspieligkeit der Versuche ist diese beobachtete Thatsache nicht ohne Bedeutung.

\section{Versuch IV.}

Ein kleiner brauner Pudel wurde ebenfalls mit Fleisch, Reis, Kartoffeln, Rohrzucker 8 Tage lang gefüttert. Der Hund nahm während der Fütterung um $1782 \mathrm{~g}$ zu. Er wird durch den Nackenstich getödtet.

Das Gewicht des darmreinen Thieres betrug $7232 \mathrm{~g}$.

Die Glykogenbestimmung ergab folgende Werthe:

(Siehe Tabelle V auf S. 206.)

Der Glykogengehalt sämmtlicher Organe beträgt:

als Zucker gerechnet . . . . . $295,43 \mathrm{~g}$

der Glykogengehalt . . . . . 273,88,

$1 \mathrm{~kg}$ Thier enthält also, da das darmreine Thier $7232 \mathrm{~g}$ wiegt, 40,897 g Zucker, resp.

37,871 , Glykogen.

Das Lebergewicht beträgt $12,43 \%$ vom Körpergewicht.

In der Leber sind $167,64 \mathrm{~g}$ Zucker, in den übrigen Organen zusammen $127,79 \mathrm{~g}$.

Es kommen also auf $100 \mathrm{~g}$ Leberglykogen $76 ; 17 \mathrm{~g}$ in den übrigen Organen.

Die Unterschiede zwischen der Kupferoxydulmethode und der Kupfermethode nach Volhard sind in folgender Tabelle VI zusammengestellt.

Tabelle VI.

\begin{tabular}{|c|c|c|c|c|}
\hline \multirow{2}{*}{ Organ } & \multicolumn{2}{|c|}{ Zucker, berechnet im mg } & \multirow{2}{*}{$\begin{array}{c}\text { Differenz } \\
\text { absolut } \\
\text { in mg }\end{array}$} & \multirow{2}{*}{$\begin{array}{c}\text { Differenz } \\
\text { in } \%\end{array}$} \\
\hline & aus $\mathrm{Cu}_{2} \mathrm{O}$ & aus $\mathrm{Cu}$ & & \\
\hline 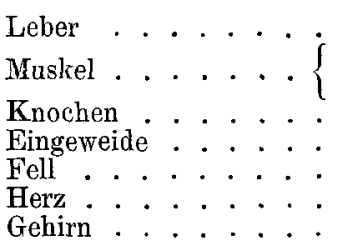 & $\begin{array}{l}189,45 \\
147 \\
137 \\
159,4 \\
208,2 \\
149,9 \\
100 \\
39,5\end{array}$ & $\begin{array}{l}186,7 \\
146,4 \\
136,1 \\
158,8 \\
20,5 \\
148,64 \\
100 \\
35,7\end{array}$ & $\begin{array}{l}-2,75 \\
-0,6 \\
-0,9 \\
-0,6 \\
-3,2 \\
-0,26 \\
-\overline{3}, 8\end{array}$ & $\begin{array}{l}-1,4 \\
-0,4 \\
-0,65 \\
-0,38 \\
-1,5 \\
-0,1 \\
-\overline{9}, 6\end{array}$ \\
\hline
\end{tabular}


Auch hier zeigt sich eine gute Uebereinstimmung zwischen der $\mathrm{Cu}_{2} \mathrm{O}$-Methode und der Cu-Methode. Nur beim Gehirn zeigt sich ein grösserer Unterschied. Dieser Unterschied ist aber leicht erklärlich. Ich habe bei den Abweiehungen von der gewöbnlichen Art der Glykogenanalyse auseinandergesetzt, dass ich beim Gehirn den durch die Alkoholfällung hervorgerufenen Glykogenniederschlag direct mit Salzsäure invertirte, weil dieser Niederschlag in Wasser sich nicht löste. Durch die Salzsäure sind dann Stoffe in Lösung gegangen, die in der stark alkalischen All i h n'schen Lauge wieder ausfielen, sich dem Kupferoxydul beimengten und dasselbe verunreinigten.

\section{Versuch V.}

Ein Fox-Terrier wird wie in Versuch III und IV gefüttert. Der Hund nahm während der Fütterung um $2018 \mathrm{~g}$ an Gewicht zu. Er wird durch den Nackenstich getödtet.

Die Glykogenbestimmung ergab folgende Werthe:

(Siehe Tabelle VII auf S. 208.)

Der Glykogengehalt sämmtlicher Organe beträgt, als Zucker gerechnet . . . . 332,64 g der Glykogengebalt . . . . 308,56 "

Der Hund enthält, da das darmreine Thier $8818 \mathrm{~g}$ wiegt:

Auf $1 \mathrm{~kg}$ Thier $37,64 \mathrm{~g}$ Zucker, resp. 34,89 "Glykogen.

Das Lebergewicht beträgt 8,23\% vom Körpergewicht.

In der Leber sind $128,24 \mathrm{~g}$ Zucker, in den übrigen Organen $204,4 \mathrm{~g}$.

Es kommen also auf $100 \mathrm{~g}$ Leberglykogen $159,3 \mathrm{~g}$ Glykogen.

Die Unterschiede in der Kupferoxydulmethode und der Kupfermethode nach Volhard sind in Tabelle VIII zusammengestellt.

T abelle VIII.

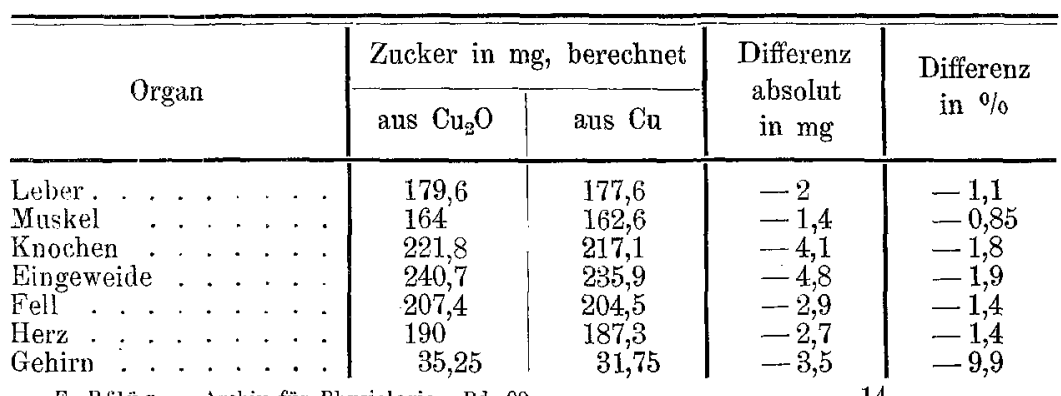




\begin{tabular}{|c|c|c|}
\hline 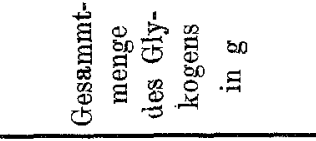 & 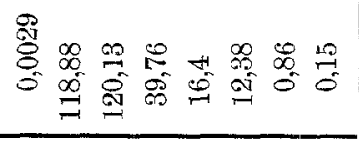 & 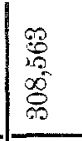 \\
\hline 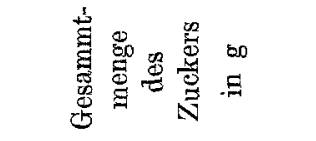 & 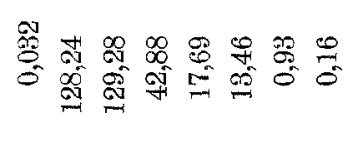 & 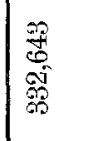 \\
\hline 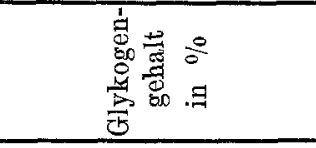 & 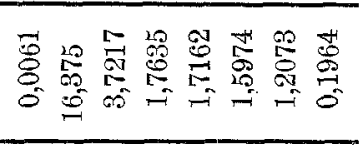 & 1 \\
\hline 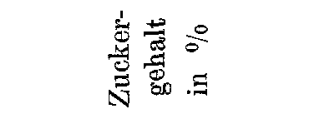 & 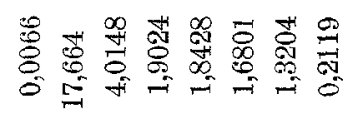 & 1 \\
\hline 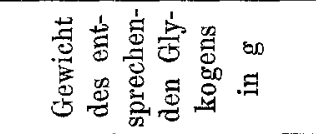 & 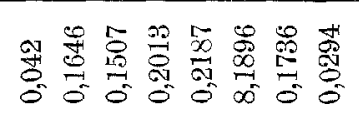 & 1 \\
\hline 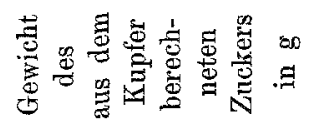 & 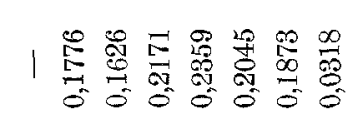 & 1 \\
\hline 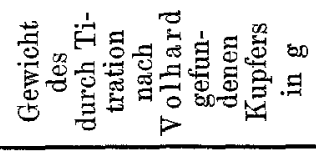 & 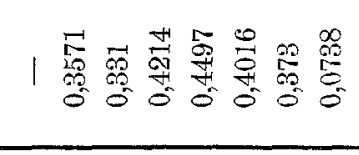 & I \\
\hline 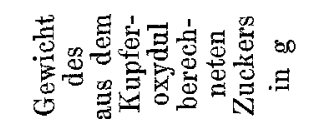 & 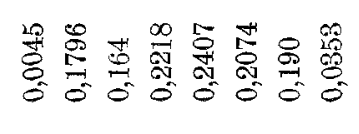 & \\
\hline 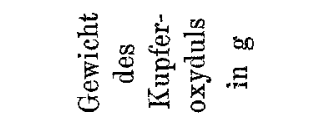 & 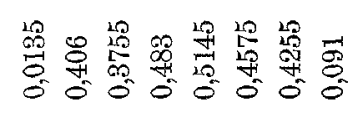 & 1 \\
\hline 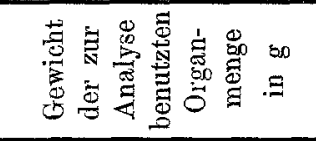 & 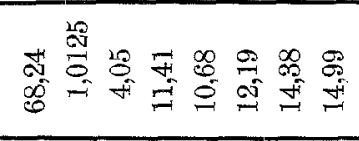 & 1 \\
\hline 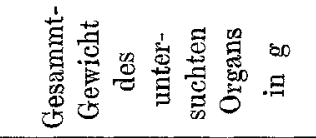 & 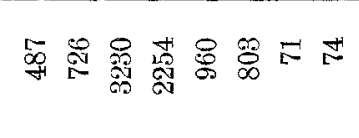 & 1 \\
\hline 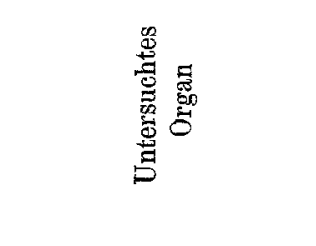 & 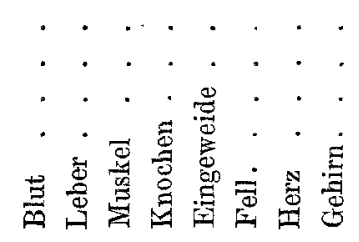 & \\
\hline
\end{tabular}


Ueber den Maximalwerth des Gesammtglykogengehalts von Hunden.

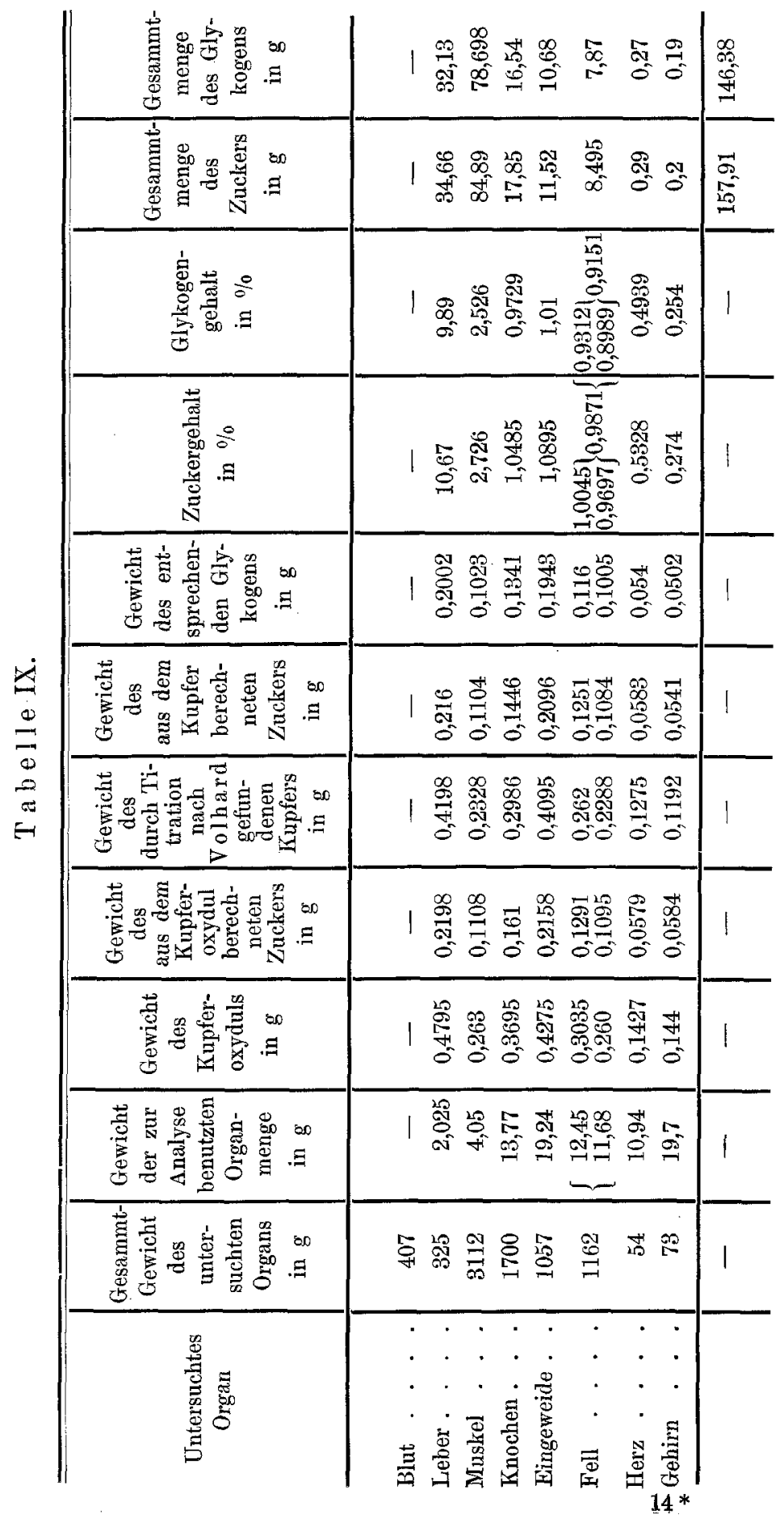


Auch hier zeigt sich eine gute Uebereinstimmung zwischen den Zuckerwerthen aus $\mathrm{Cu}_{2} \mathrm{O}$ und aus $\mathrm{Cn}$ berechnet. Nur beim Gehirn findet sich der schon oben begründete grössere Unterschied.

\section{Versueh VI.}

Ein Wolfsspitz wird nach achttägigem Hungern mit Fleisch, Reis, Kartoffeln und Rohrzucker gefüttert. Der Hund hatte zwei Tage lang nach der Brotfütterung Diarrhöe. Der Hund nahm während der Fütterung um $809 \mathrm{~g}$ an Gewicht zu.

Er wurde durch den Nackenstich getödtet. Das darmreine Thier wiegt $8009 \mathrm{~g}$.

Die Glykogenbestimmung ergab folgende Werthe:

(Siehe Tabelle IX auf S. 209.)

Der Glykogengehalt sämmtlicher Organe beträgt also :

als Zucker gerechnet . . . . $157,91 \mathrm{~g}$

der Glykogengehalt. . . . . 146,38,

Da das darmreine Thier $8009 \mathrm{~g}$ wiegt, so enthält

$1 \mathrm{~kg}$ Thier $19,72 \mathrm{~g}$ Zucker, resp.

18,28 "Glykogen.

Das Lebergewicht beträgt $\mathbf{4 , 0 6 \%}$ vom Körpergewicht.

In der Leber sind $34,66 \mathrm{~g}$ Zucker, in den übrigen Organen sind $123,25 \mathrm{~g}$. Es kommen also auf $100 \mathrm{~g}$ Leberglykogen $\mathbf{3 5 5 , 6 5} \mathrm{g}$ Glykogen. In den übrigen Organen ist also ungefähr die $3 \mathbf{1} / \mathbf{2}$ fache Menge Glykogen, wie in der Leber.

Die Unterschiede in der Kupferoxydulmethode und Kupfermethode nach $\mathrm{Volh}$ ard sind in Tabelle $\mathrm{X}$ zusammengestellt.

Tabelle X.

\begin{tabular}{|c|c|c|c|c|}
\hline \multirow{2}{*}{ Organ } & \multicolumn{2}{|c|}{ Zucker in mg, berechnet } & \multirow{2}{*}{$\begin{array}{c}\text { Differenz } \\
\text { absolut } \\
\text { in } \mathrm{mg}\end{array}$} & \multirow{2}{*}{$\begin{array}{c}\text { Differenz } \\
\text { in } \%\end{array}$} \\
\hline & aus $\mathrm{Cu}_{2} \mathrm{O}$ & aus $\mathrm{Cu}$ & & \\
\hline $\begin{array}{l}\text { Leber. . . . . . . . : } \\
\text { Muskel . . . . . . . } \\
\text { Knochen . . . . . . } \\
\text { Eingeweide . . . . . } \\
\text { Fell . . . . . . . . } \\
\text { Herz . . . . . . . . : } \\
\text { Gehirn . . . . . . . . }\end{array}$ & $\begin{array}{l}219,75 \\
110,8 \\
161,0 \\
215,8 \\
129,1 \\
109,4 \\
57,85 \\
58,37\end{array}$ & $\begin{array}{l}216 \\
110,4 \\
144,5 \\
209,6 \\
125,1 \\
108,4 \\
58,25 \\
54,1\end{array}$ & $\begin{array}{l}-3,75 \\
-0,4 \\
-17,15 \\
-6,2 \\
-4,0 \\
-1,0 \\
+0,4 \\
-4,26\end{array}$ & $\begin{array}{l}-1,7 \\
-0,36 \\
-10,9 \\
-2,9 \\
-3,1 \\
-0,91 \\
+0,7 \\
-7,3\end{array}$ \\
\hline
\end{tabular}

Die Berechnung des Zuckers aus dem $\mathrm{Cu}_{2} \mathrm{O}$ und dem titrirten $\mathrm{Cu}$ zeigt ungefähr dieselben Unterschiede, wie in den früheren. Nur 
bei den Knochen zeigt sich diesmal ein grösserer Unterschied. Dies ist dadurch bedingt, dass bei dieser Analyse das ganze gefällte Glykogen rom Filter genommen, in Wasser gelöst und ohne zu filtriren invertirt wurde. Durch die Salzsäure wurden gewisse Stoffe gelöst, die in der alkalischen Allihn'schen Lauge wieder ausfielen und sich dem $\mathrm{Cu}_{2} \mathrm{O}$ beimengten.

\section{Versuch VII.}

Fin schwarzer Spitz wird nach achttägigem Hungern mit derselben Nahrung gefüttert, wie die vier letzten Hunde, also $200 \mathrm{~g}$ Fleisch, $100 \mathrm{~g}$ Reis, $150 \mathrm{~g}$ Kartoffeln und $150 \mathrm{~g}$ Rohrzucker. Sein Gewicht nahm um $1152 \mathrm{~g}$ zu.

Er wurde durch den Nackenstich getödtet. Das darmreine Thier wiegt $7452 \mathrm{~g}$.

Die Glykogenbestimmung ergab folgende Werthe:

(Siehe Tabelle XI auf S. 212.)

Der Glykogengehalt sämmtlicher Organe beträgt also:

$$
\begin{aligned}
& \text { als Zucker gerechnet . . . . . 61,04 g } \\
& \text { der Glykogengehalt . . . . . 57,13 g }
\end{aligned}
$$

Da das darmreine Thier $7452 \mathrm{~g}$ wiegt, so enthält

$$
1 \mathrm{~kg} \text { Thier . . . . } \begin{array}{r}
8,191 \mathrm{~g} \text { Zucker resp., } \\
7,593 \mathrm{~g} \text { Giykogen. }
\end{array}
$$

Das Lebergewicht beträgt 5,1\% vom Körpergewicht.

In der Leber sind $29,76 \mathrm{~g}$ Zucker, in den übrigen Organen $31,28 \mathrm{~g}$ Zucker. Es kommen also auf $100 \mathrm{~g}$ Glykogen in der Leber $105,1 \mathrm{~g}$ Glykogen in den übrigen Organen, also fast dieselbe Menge.

Die Unterschiede zwischen den Zuckerwerthen nach der $\mathrm{Cu}_{2} \mathrm{O}$ -

\begin{tabular}{|c|c|c|c|c|}
\hline \multirow{2}{*}{ Organ } & \multicolumn{2}{|c|}{ Zucker in $\mathrm{mg}$, berechnet } & \multirow{2}{*}{$\begin{array}{c}\text { Differenz } \\
\text { absolut } \\
\text { in } \mathrm{mg}\end{array}$} & \multirow{2}{*}{$\begin{array}{c}\text { Differenz } \\
\text { in } \%\end{array}$} \\
\hline & aus $\mathrm{Cu}_{2} \mathrm{O}$ & aus $\mathrm{Cu}$ & & \\
\hline 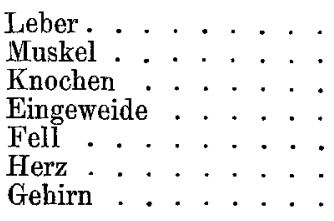 & $\begin{array}{l}163,8 \\
66,3 \\
42,65 \\
35,5 \\
13,35 \\
34,6 \\
28,15\end{array}$ & $\begin{array}{c}159,4 \\
66,4 \\
42,1 \\
35,05 \\
11,75 \\
34,7 \\
27,35\end{array}$ & $\begin{array}{l}-4,4 \\
+0,1 \\
-0,55 \\
-0,45 \\
-1,6 \\
+0,1 \\
-0,8\end{array}$ & $\begin{array}{l}-2,7 \\
+0,15 \\
-1,3 \\
-1,3 \\
-12,0 \\
+0,3 \\
-2,8\end{array}$ \\
\hline
\end{tabular}
Analyse und der Cu-Analyse nach Volhard sind in Tab. XII zusammengestellt.

Tabelle XII. 


\begin{tabular}{|c|c|c|}
\hline 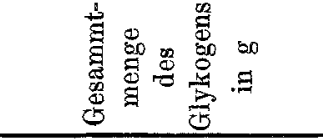 & 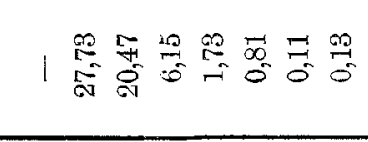 & $\stackrel{20}{10}$ \\
\hline 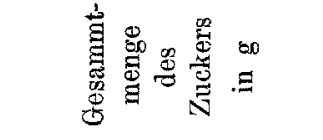 & 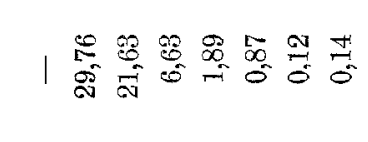 & $\frac{d}{0}$ \\
\hline 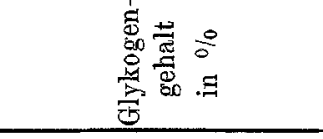 & 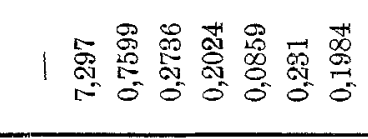 & 1 \\
\hline 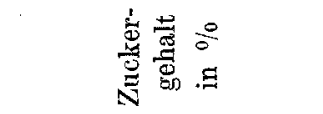 & 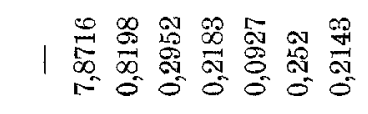 & 1 \\
\hline 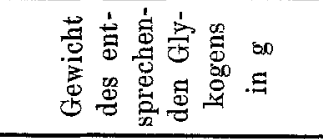 & 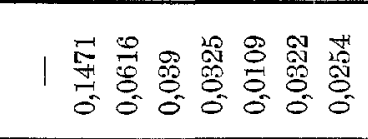 & 1 \\
\hline 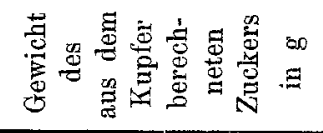 & 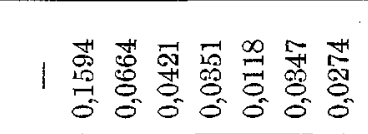 & 1 \\
\hline 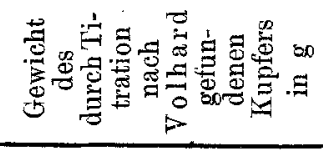 & 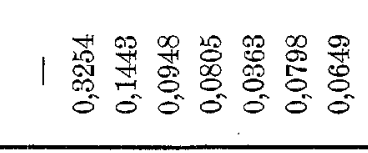 & 1 \\
\hline 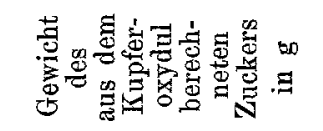 & 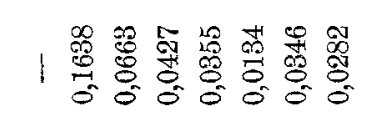 & 1 \\
\hline 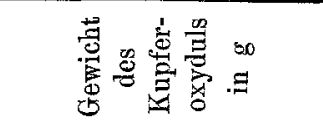 & 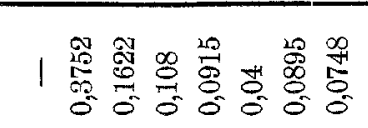 & 1 \\
\hline 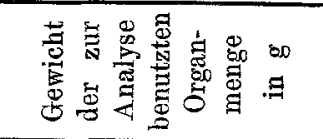 & 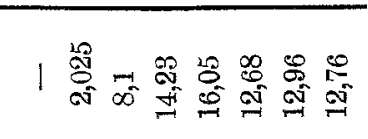 & 1 \\
\hline 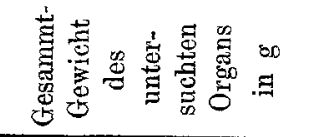 & 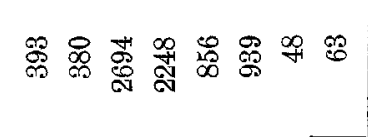 & 1 \\
\hline 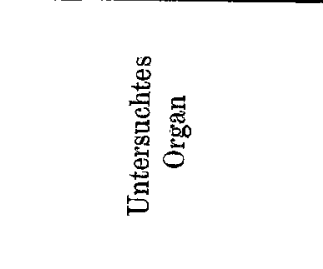 & 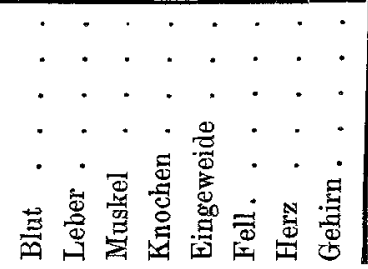 & \\
\hline
\end{tabular}


Es ergeben also auch hier beide Analysen ungefähr dieselben Unterschiede wie in den früheren Versuchen.

\section{Versuch VIII.}

Ein Fox-Terrier wiegt nach achttägigem Hungern 5870 g. Er erhält acht Tage lang dieselbe Nahrung wie die letzten Hunde. Sein Gewicht nahm um $930 \mathrm{~g}$ zu. Der Hund wurde von Herrn Lö s chke zu anderen $\mathrm{Zwecken}$ benutzt.

Die Leber wog $485 \mathrm{~g}$, und ihr Gewicht beträgt $7,15 \%$ vom Körpergewicht.

Der Glykogengehalt der Leber betrug, als Zucker berechnet, $16,17 \%$.

Fassen wir die Ergebnisse der Versuche bezüglich des Gesammtglykogengebaltes pro Kilo Thier zusammen, so ergeben sich, für das Kilo Thier gerechnet, folgende Zahlen. Es werden beide Werthe angegeben, sowohl die aus dem $\mathrm{Cu}$-Werth berechnete Zuckermenge, als auch die durch Multiplication mit dem Factor 0,927 gefundene Glykogenmenge. $1 \mathrm{~kg}$ Thier enthält:

\begin{tabular}{c|c|c}
\hline Versuch & $\begin{array}{c}\text { Zucker } \\
\mathrm{g}\end{array}$ & $\begin{array}{c}\text { Glykogen } \\
\mathbf{g}\end{array}$ \\
\hline & & 6,23 \\
I & 7,75 & 5,78 \\
III & 32,49 & $\mathbf{7 , 1 8}$ \\
IV & $\mathbf{4 0 , 8 9 7}$ & 30,07 \\
V & 37,64 & $\mathbf{3 7}, \mathbf{8 7}$ \\
VI & $\mathbf{1 9 , 7 2}$ & 34,89 \\
VII & 8,19 & 18,28 \\
& & $\mathbf{7 , 5 9}$
\end{tabular}

Es geht daraus hervor, dass der Maximalwerth von $40,897 \mathrm{~g}$ Zucker, resp. 37,87 $\mathrm{g}$ Glykogen pro Kilo Thier weit über den von E. Voit beobachteten höchsten Werth von 22 g pro Kilo Thier bei der Gans geht.

Es geht ferner aus den Versuchen hervor, welche kolossalen Schwankungen bei Hunden, dieauf dieselbe Art gefüttert worden sind, vorkommen.

Der niedrigste beobachtete Werth bei den sechs Hunden, die mit Fleisch, Reis, Kartoffeln und Rohrzucker gefüttert worden sind, beträgt:

$8,19 \mathrm{~g}$, bezw. $7,59 \mathrm{~g}$ prokg Thier, 
der höchste

40,897 g, bezw. 37,87 g prokg Thier.

Der Maximalwerth ist also ungefähr fünf Mal so gross wie de: Minimalwerth.

Wenn man nun bedenkt, dass unsere Versuche im Sommer ausgeführt worden sind und die Versuche von $\mathrm{Gürber}{ }^{1}$ ) an Kaninchen gezeigt haben, dass dieselben im Sommer viel weniger Glykogen enthalten als im Winter, so ist nicht mit Sicherheit zu sagen, dass der von uns beobachtete Maximalwerth von $40 \mathrm{~g}$ pro kg Thier wirklich der höchste Werth ist, der vorkommen kann. Es wäre immerhin möglich, dass bei Fütterungsversuchen im Winter sich noch höhere Werthe ergeben. Ich behalte mir desshalb vor, den Mästungsversuch auf Glykogen im Winter nochmals zu wiederholen.

Es zeigen ferner die Versuche, dass man gar nicht nöthig hat, maximale Glykogenmengen in einem Hunde anzunehmen, um bei den Phloridzindiahetes-Versuchen den ausgeschiedenen Zucker aus dem vorhandenen Glykogen zu erklären. Z. B. bei der grossen Dogge von $60 \mathrm{~kg}$ in dem Versuche von Schumm und Hartogh würde ein mittlerer Glykogengehalt von $20 \mathrm{~g}$ pro $\mathrm{kg}$ Thier genügen, um allen ausgeschiedenen Zucker zu erklären.

Es ist zuweilen der Gesammtglykogengehalt eines Thieres bestimmt worden, dass man die Glykogenmenge der Leber bestimmt und die Glykogenmenge des übrigen Körpers berechnet, indem man die Annahme macht, dass in dem Körper der Thiere mindestens ebensoviel Glykogen sei wie in der Leber. Wenn wir nun unsere Versuche daraufhin betrachten, so ergibt sich, dass diese Art, den Glykogengehalt eines ganzen Thieres zu berechnen, zu sehr grossen Fehlern Veranlassung geben kann.

Setzen wir das Gewicht des Leberglykogens gleich 100, so ergeben unsere Versuche Folgendes:

Auf $100 \mathrm{~g}$ Leberglykogen kommen im übrigen Körper, das Glykogen als Zucker berechnet:

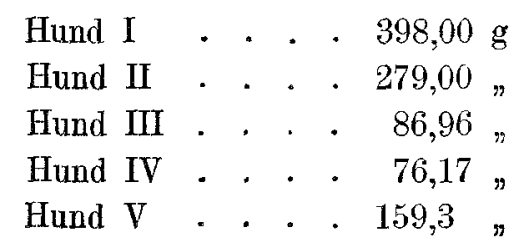

1) Sitzungsber. d. phys.-med. Gesellsch. S. 17. Würzburg 1895. 
Ueber den Naximalwerth des Gesammtglykogengehalts von Hunden. 215

$$
\begin{aligned}
& \text { Hund VI . . . . . } 355,65 \mathrm{~g} \\
& \text { Hund VII . . . . } 105,1 \text { " }
\end{aligned}
$$

Es ist also nur in einem einzigen Falle die Glykogenmenge der Leber ungefähr gleich der Glykogenmenge des übrigen Körpers, zuweilen ist die Glykogenmenge des übrigen Körpers kleiner als die der Leber, sie kann aber bis zur vierfachen Menge der Leber steigen.

Auch bezüglich des Glykogengehaltes der einzelnen Organe ergeben die Versuche Werthe, wie sie nie beobachtet sind. Ziehen wir zunächst die Leber in Betracht, so ergeben unsere Versuche:

\begin{tabular}{c|c|c}
\hline Versuch & $\begin{array}{c}\text { Zucker } \\
\% \text { \% }\end{array}$ & $\begin{array}{c}\text { Glykogen } \\
\% \%\end{array}$ \\
\hline I & 4,697 & 4,354 \\
II & 8,197 & 7,602 \\
III & 20,17 & 18,69 \\
IV & 18,44 & 17,1 \\
VI & 17,66 & 16,38 \\
VII & $\mathbf{1 0 , 6 7}$ & 9,89 \\
VIII & 7,87 & 7,3 \\
& 16,17 & 14,99
\end{tabular}

Es zeigen die Versuche also, wie gross bei gleicher Fütterung die Schwankungen im Glykogengehalt der einzelnen Organe sind.

Der niedrigste Werth beträgt $7,87 \%$ bezw. $7,3 \%$, der höchste . . . . . . 20,17\%, $18,69 \%$.

Die höchsten bis jetzt beobachteten Werthe über den Glykogengehalt der Leber waren

$$
\begin{aligned}
& \text { für Hunde . . 12,6 \% [Pavy } \left.\left.{ }^{1}\right)\right] \\
& \text { "Hühner . . 14,7 \% [Tscherin off } \left.\left.{ }^{2}\right)\right] \\
& \text { "Gans. . 10,51\% [E. Vo it } \left.\left.{ }^{3}\right)\right] \\
& \text { "Huhn. . 1 11,8 \% [Hergenhahn }{ }^{4} \text { ] } \\
& \text { "Huhn. . } \left.\left.7,8 \% \text { [Prausnitz }{ }^{5}\right)\right] \\
& \text { "Huhn. . . 10,0\% [E. Külz } \left.\left.{ }^{6}\right)\right] \\
& \text { "Huhn. . . 15,3 \% [0 t to } \left.\left.{ }^{7}\right)\right] \\
& \text { "Kaninchen . 16,85\% [ " ] }
\end{aligned}
$$

1) F. W. Pary, The Physiology of the Carbohydrates p. 127.

2) Virchow's Archiv Bd. 47 S. 113.

3) Zeitschr. f. Biol. Bd. 25 S. 546.

4) Zeitschr. f. Biol. Bd. 27 S. 115.

5) Zeitschr. f. Biol. Bd. 26 S. 389.

6) E. Külz, Beiträge zur Kenntniss des Glykogens S. 104.

7) Zeitschr. f. Biol. Bd. 28 S. 253. 
Der von uns beobachtete Maximalwerth ist also fast doppelt so gross wie der von Pavy beobachtete, der desshalb sicher gestellt ist, weil er das Glykogen invertirte und den Zucker bestimmte, während bei den andern Angaben das Glykogen gewogen worden ist.

Die von Pavy und Pflüger beohachtete Erscheinung, dass eine sebr glykogenreiche Leber sehr weich ist, so dass sie bei geringem Druck zerreisst, konnte ich ebenfalls bestätigen.

Ich habe ferner eine Beobachtung gemacht bezüglich der Frage, ob das Glykogen gleichmässig in den einzelnen Leberstücken vertheilt ist. Nach den bisher vorliegenden Versuchen von $R$. K ̈̈̈lz z) und Cramer ${ }^{2}$ ) und Seegen und Kratsehmers) nahm man an, dass das Glykogen in der Leber wenigstens annähernd gleich vertheilt ist, wenn anch die beobachteten Unterschiede besonders bei kleineren Thieren nicht so ganz gering sind und in einem Versuch von $\mathrm{R}$. Kü $\mathrm{lz}$ bis $\mathrm{zu} 11,9 \%$ betrug.

Nachdem wir in Versuch III vermeintlich die ganze Leber herausgenommen hatten, die $605 \mathrm{~g}$ wog, entdeckten wir ein paar Minuten nachher, als wir die Eingeweide herausnahmen, dass wir noch einen Lappen von $214 \mathrm{~g}$, der ganz nach hinten lag, übersehen hatten. Die beiden Lappen wurden getrennt analysirt. Der zunächst herausgenommene Theil von $605 \mathrm{~g}$ enthielt $20,28 \%$ Zucker, der zweite Theil von $214 \mathrm{~g}$ enthielt $19,88 \%$ Zucker, also ein Unterschied von ungefähr $2 \%$.

Es geht daraus hervor, dass das Glykogen in unserem Versuche gleichmässig ungefähr auf beide Leberstücke vertheilt war.

Was die Beziehung des Iebergewichts zum Körpergewicht betrifft, so ergaben unsere Versuche folgende Ergebnisse:

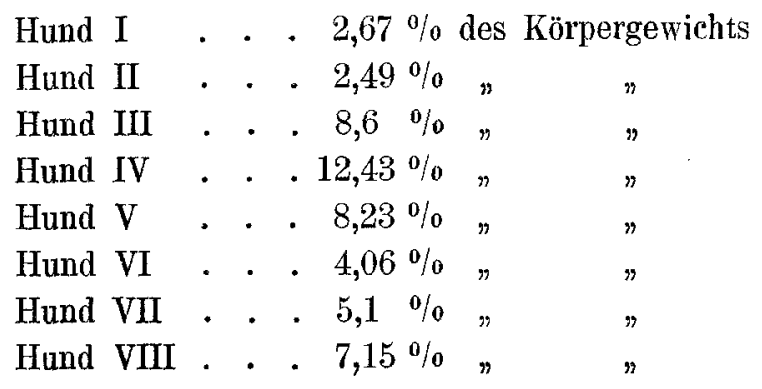

1) Zeitschr. f. Biol. Bd. 22 S. 183.

2) Zeitschr. f. Biol. Bd. 24 S. 85.

3) Pflüger's Archiv Bd. 22 S. 223. 
Der Minimalwerth beträgt 2,49\%, der Maximalwerth $12,43 \%$. Im Mittel aus allen Versuchen macht die Leber $\mathbf{6 , 3 4} \%$ des Körpergewichts aus.

Nimmt man aber nur die Lebern der Hunde, die auf dieselbe Art gefüttert waren, so beträgt das Minimum 4,06\%, das Maximum $12,43 \%$, der mittlere Werth 7,59\%. $\mathrm{Pavy}^{1}$ ) hatte als mittleren Werth aus 5 Versuchen bei kohlehydratreicher Nahrung $\mathbf{6 , 4} \%$, als Minimalwerth $4,8 \%$, als Maximalwerth $9,5 \%$, während er bei animalischer Nahrung als mittleren Werth $3,3 \%$, als Minimalwerth $3 \%$, als Maximalwerth 4,7\% fand. Meine Versuche stimmen also mit den Versuchen Pavy's überein.

Auch bei der Betrachtúng des Glykogengehalts der Muskeln finden sich abnorm hohe Werthe, wie siebisher nie beobachtet sind.

Er ergibt sich als Glykogengehalt der Muskeln:

\begin{tabular}{|c|c|c|c|}
\hline & & Zuckergehalt & Glykogengehalt \\
\hline Hund I & & 0,78 & 0,72 \\
\hline Hund II & . & 0,95 & 0,88 \\
\hline Hund III & . & . 2,74 & 2,54 \\
\hline Hund IV & . & . $\quad 3,49$ & 3,23 \\
\hline Hund V & . & 4,01 & 3,72 \\
\hline Hund VI & . & - 2,73 & 2,53 \\
\hline Hund VII & . & . 0,82 & 0,76 \\
\hline
\end{tabular}

Es zeigt sich auch hier, dass bei derselben Fütterung ganz bedeutende Schwankungen im Glykogengehalt der Muskeln vorkommen.

Der Minimalwerth beträgt:

0,78\% Zucker, bezw. 0,72\% Glykogen.

Der Maximalwerth:

4,01\% Zucker, bezws 3,72\% Glykogen.

Die höchsten bisher beobachteten Werthe sind:

Pferd . . . . 2,44\% [A ld e h of f $\left.\left.{ }^{2}\right)\right]$

Neugeborenes Kind 1,85\% [ $\left.\left.\mathrm{Cramer}^{3}\right)\right]$.

Was die übrigen Organe betrifft, so ergaben alle Versuche, dass ausser in der Leber und den Muskeln auch in den übrigen Organen ganz beträchtliche Glykogenmengen vorkommen können. Ich gebe

1) Pavy, The Physiology of the Carbohydrates p. 114.

2) Zeitschr. f. Biologie Bd. 25 S. 147.

3) Zeitschr. f. Biologie Bd. 24 S. 75. 
im Folgenden die Werthe für den Glykogengehalt der Organe als Zucker gerechnet:

\begin{tabular}{|c|c|c|c|}
\hline & & & Knochen \\
\hline Hund I & & . & $0,197 \quad \mathbf{0}_{/ 0}$ \\
\hline Hund II & . & . & $0,4234 \%$ \\
\hline Hund III & . & & $58 \%$ \\
\hline Hund IV & 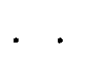 & & $1,4163 \%$ \\
\hline Hund V & & & $1,9024 \%$ \\
\hline Gund VI & & & $1,0485 \%$ \\
\hline und VII & & & $0,2952 \%$ \\
\hline
\end{tabular}

Der niedrigste Werth beträgt:

der höchste:

$$
0,197 \% \text {, }
$$

$$
1,9024 \% \text {. }
$$

\begin{tabular}{|c|c|c|c|}
\hline & & & \\
\hline und II & & & \\
\hline III & & & \\
\hline and I & & & \\
\hline Iund & & & . 1,8 \\
\hline und $V$ & & & 1,089 \\
\hline und VII & & & $0,2183^{\circ}$ \\
\hline
\end{tabular}

Der niedrigste Wertb beträgt:

der höchste:

$$
0,0264 \% \text {, }
$$

$$
1,8428 \%
$$

\section{Fell}

Hund I . . . . 0,4051\%

Hund II • . . . 0,2157\%

Hund III . . . . 0,7833\%

Hund IV . . . . 0,9051\%

Hund V . . . 1,6801\%

Hund VI . . . 0,9871\%

Hund VII . . . 0,0927\%.

Der niedrigste Werth beträgt:

der höchste:

$$
0,0927 \% \text {, }
$$

$$
1,6801 \% \text {. }
$$


Herz

\begin{tabular}{|c|c|c|c|}
\hline Hund I & . & & $0,127 \%$ \\
\hline Hund II & . & & $0,1047 \%$ \\
\hline Hund III & & & $0,6274 \%$ \\
\hline Hund IV & ( & & $0,7716^{\circ / 0}$ \\
\hline Hund V & & & $1,3204 \%$ \\
\hline Hund VI & . & . & $0,252 \quad \%$ \\
\hline Hund VII & . & & $0,5328^{\circ} \%$ \\
\hline
\end{tabular}

Der niedrigste Werth beträgt:

der höchste:

$$
0,1074 \%
$$

$$
1,3204 \% \text {. }
$$

\begin{tabular}{|c|c|c|}
\hline & & Gehirn \\
\hline fund I & . & . $0,0469 \%$ \\
\hline Aund II & & $0,2463 \%$ \\
\hline und III & . & $0,287 \quad 0 / 0$ \\
\hline Hund IV & & $0,2449 \%$ \\
\hline and $V$ & • & $0,2119 \%$ \\
\hline und VI & & $0,2143^{\%} / 0$ \\
\hline and VII & & $0,274 \quad \%$ \\
\hline
\end{tabular}

Der niedrigste Werth beträgt:

der höchste:

$$
0,0469 \%
$$

$$
0,287 \% \text {. }
$$

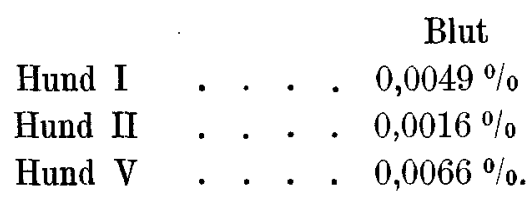

Bei den übrigen Hunden wurde das Glykogen im Blut nicht bestimmt. Der Glykogengehalt des Blutes schwankt also von 0,0016 bis $0,0066 \%$.

In seinen Vorsehriften für die Ausführung einer Glykogenanalyse gibt Pflüg er an, dass man das gefällte Glykogen schon nach einer Viertelstunde abfiltriren könne, dass man aber sicherer einige Stunden, am besten über Nacht wartet, ehe man filtrirt. Wenn man aber nun sehr viele Glykogenbestimmungen zu machen hat, wie bei unseren Versuchen, so ist es natürlich nicht immer möglich, alle Analysen am nächsten Tage weiter fortzusetzen, sondern man 
ist zuweilen gezwungen, das gefällte Glykogen mehrere Tage stehen zu lassen, ehe man es abfiltrirt. Es fragt sich nun, ob man diess thun kann, ohne befürchten zu müssen, dass das Glykogen sich zersetzt und man niedrigere Werthe für den Glykogengebalt des untersuchten Organs erhält.

Als wir die abnorm hohen Werthe für den Glykogengehalt der Organe fanden, entschlossen wir uns, um unsere Versuche sicher zu stellen, die Titration des $\mathrm{Cu}$ nach Volhard in dem gewogenen $\mathrm{Cu}_{2} \mathrm{O}$ auszufübren. Nun waren von Versuch III die meisten Zuckerbestimmungen und von den anderen Versuchen einzelne Zuckerbestimmungen schon ausgeführt und die Zuckerlösungen weggegossen. Es mussten also, um die Titration des Kupfers nach Volhard ausführen zu können, die Controlglykogenanalysen, die aufbewahrt worden waren, in Arbeit genommen werden.

Das Glykogen wurde nach drei Wochen abfiltrirt und mit demselben die Zuckerbestimmungen ausgeführt. Es stellte sich dabei heraus, dass man dieselben Werthe erhielt, ob man das Glykogen sofort abfiltrirte oder erst nach drei Wochen. Es wird aber der Sicherheit wegen doch zweckmässig sein, die Glykogenfällung mit einem Uhrglas gut zuzudecken und dafür zu sorgen, dass der Alkobol nicht zu stark verdunstet, also die Gläser an einem kühlen Ort aufaubewahren und eventuell den verdunsteten Alkohol ersetzen, was auch bei unseren Versuchen gesehehen ist.

Ich gebe in der folgenden Tabelle 12 die Kupferoxydulwerthe, die mit dem sofort filtrirten Glykogen erhalten wurden und die mit dem nach drei Wochen filtrirten. Die Zahlen beziehen sich natürlich immer auf dieselbe Menge Organ.

Fasse ich die Hauptergebnisse der Versuche noch einmal kurz zusammen, so haben dieselben also ergeben:

1. $1 \mathrm{~kg} H u n d$ kann bei reichlicher Ernähung mit Fleisch und Kohlehydraten in maximo 40,897 $\mathrm{g}$ Zucker, resp. $37,87 \mathrm{~g}$ Glykogen enthalten.

2. Es kommen bei der Füterung von Hunden mit derselben Nahrung riesige Schwankungen im Gesam m tglykogengehalt vor.

Der niedrigste Werth beträgt pro Kilogramm Thier:

$8,19 \mathrm{~g} \mathrm{Zucker,} \mathrm{bezw.} 7,59 \mathrm{~g}$ Glykogen, der höchste:

40,897 g Zucker bezw. 37,87 g Glykogen. 
Tabelle XII.

\begin{tabular}{c|c|c}
\hline Organ & Glykogen sofort abfiltrirt & $\begin{array}{c}\text { Glykogen nach drei Wochen } \\
\text { abfiltrirt }\end{array}$ \\
\hline
\end{tabular}

Versuch III.

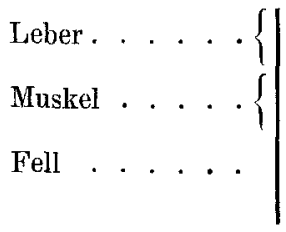

Leber. . . . $\{1$

Leber. . . . $\{\mid$

$\begin{array}{llc}457,5 & \mathrm{mg} & \mathrm{Cu}_{2} \mathrm{O} \\ 456 & " & " \\ 136,5 & " & " \\ 132 & " & " \\ 233 & " & "\end{array}$

Versuch IV.

$428,5 \mathrm{mg} \mathrm{Cu}_{2} \mathrm{O}$ 425,3 " "

Versuch V.

$409,5 \mathrm{mg} \mathrm{Cu} 2 \mathrm{O}$ 403,8 " "

$\begin{array}{lcc}459,5 & \mathrm{mg} & \mathrm{Cu}_{2} \mathrm{O} \\ 457,5 & " & " \\ 136,8 & " & " \\ 138,5 & " & " \\ 240,5 & " & " \\ 238 & " & \end{array}$

$424,5 \mathrm{mg} \mathrm{Cu}_{2} \mathrm{O}$

3. Bei dem Vergleich des Glykogengehaltes der Leber mit dem des übrigen Körpers kommen ebenfalls solche grosse Schwankungen vor.

Auf 100 g Leberglykogen können kommen im übrigen Körper $\mathbf{7 6 , 1 7}$ bis $398 \mathrm{~g}$.

4. Der beobachtete Maximalglykogengehalt der Leber beträgt 20,17\% Zucker, bezw. 18,69\% Glykogen.

5. In einem Versuche war in versebiedenen Leberlappen ungefähr die gleiche Menge Glykogen, $20,28 \%$ und $19,88 \%$.

6. Die Beziehung des Lebergewichts zum Körper gewicht ergab bei reichlicher Kohlehydratnahrung als Minimalwerth $2,49 \%$, als Maximalwerth $12,43 \%$, im Mittel 6,34\%.

7. Der Glykogengehalt der Muskeln schwankt zwischen $0,78 \%$ Zucker, bezw. $0,72 \%$ Glykogen als niedrigsten und

4,01\% Zucker, bezw. 3,72\% Glykogen als höchsten Werth.

8. Ausser Leber und Muskeln enthalten auch alle übrigen. Organe ganz beträchtliche Mengen von Glykogen. 
9. Auch bei Anwendung des gewöhnlichen, mit Alkohol gereinigten Kaliumhydrats ergibt die Bestimmung des Zuckers durch Wägung des Kupferoxyduls richtige Werthe, falls die Waschung des Glykogens mit Kaliumbydrat Merck Ia geschieht, wie die Titration des Kupfers im Kupferoxydul nach der Volhard'schen Methode erwiesen hat.

10. Es ist nicht nothwendig, das gefällte Glykogen am nächsten Tage schon abzufiltriren, sondern man kann damitlängereZeit warten, biszudrei Wochen. Man muss nur dafür sorgen, dass die Bechergläser gut zugedeckt an einem kühlen Orte aufbewahrt werden und der verdunstete Alkohol eventuell erneuert wird.

Herrn Geheimrath Pflüger spreche ich für die Anregung und die vielfache Hülfe, die er mir bei dieser Arbeit hat zu Theil werden lassen, meinen herzlichsten Dank aus.

\section{Analytische Belege.}

\begin{tabular}{|c|c|c|c|c|c|c|}
\hline \multicolumn{7}{|c|}{ Versuch I. } \\
\hline Gewicht & des Hundes & . & . & . & & $12000 \approx$ \\
\hline$n$ & "Blutes. . & . & . & . & 。 & 530 \\
\hline$n$ & der Leber. & & . & . & & 320 \\
\hline & Muskulatur & des $h$ & alben & Hun & ndes & 3014 , \\
\hline$"$ & "Knochen do & es hall & ben $\mathrm{H}$ & Iund & des & 1016 \\
\hline$n$ & Eingeweide & ohne & Inhalt & & . & 1058 \\
\hline$n$ & des Fells & 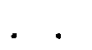 & . . & & & 2103 \\
\hline ; & $"$ Herzens & . & . & . & . & 101 \\
\hline & " Gehirns & 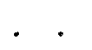 & $\cdot$ & 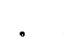 & . & 61 \\
\hline & "darmreinen & Hund & & & • & 12000 \\
\hline
\end{tabular}

1. Glykogenbestimmung im Blute.

$530 \mathrm{~g}$ Blut werden mit dem fünffachen Volumen Alkohol versetzt. Nach zwei Tagen wird der Alkubol abfiltrirt, der Niedersehlag in $30 \% \mathrm{KOH}$ gelöst und auf $2000 \mathrm{cem}$ verdünnt. Das Glykogen von $1000 \mathrm{cem}=265 \mathrm{~g}$ Blut wird in $200 \mathrm{ccm}$ invertirt.

In $81 \mathrm{~cm}$ Zuckerlösung $=107,33 \mathrm{~g}$ Blut gefunden: 
Ueber den Maximalwerth des Gesammtglykogengehalts von Hunden.

1. $16,0 \mathrm{mg} \mathrm{Cu}_{2} \mathrm{O}$,

2. $13,8 "$, .

$16 \mathrm{mg} \mathrm{Cu}_{2} \mathrm{O}=5,3 \mathrm{mg}$ Zucker $=4,9 \mathrm{mg}$ Glykogen.

Im Blute sind $0,0049 \%$ Zucker $=0,0046 \%$ Glykogen.

In $530 \mathrm{~g}$ Blut sind $0,026 \mathrm{~g}$ Zucker $=0,024 \mathrm{~g}$ Gly kogen.

2. Glykogenbestimmung in der Leber.

Das Glykogen von $25 \mathrm{~g}$ Leber in $500 \mathrm{ccm}$ invertirt.

In $81 \mathrm{ccm}$ Zuckerlösung $=4,05 \mathrm{~g}$ Leber gefunden

$$
\begin{aligned}
& \text { 1. } 426 \mathrm{mg} \mathrm{Cu} \mathrm{Cu}_{2} \mathrm{O} \text {, } \\
& \text { 2. } 423 \mathrm{mg} \mathrm{Cu}_{2} \mathrm{O} \text {, } \\
& \text { 3. } 424,7 \mathrm{mg} \mathrm{Cu} 2 \text {, } \\
& \text { 4. } 425 \mathrm{mg} \mathrm{Cu}_{2} \mathrm{O} \text {. }
\end{aligned}
$$

$426 \mathrm{mg} \mathrm{Cu}{ }_{2} \mathrm{O}=190,25 \mathrm{mg}$ Zucker $=176,4 \mathrm{mg}$ Glykogen.

In der Leber sind 4,697\% Zucker $=4,354 \%$ Glykogen.

In $320 \mathrm{~g}$ Leber sind 15,02 g Zucker $=13,93 \mathrm{~g}$ Glykogen.

Das Lebergewicht beträgt $2,67 \%$ vom Körpergewicht.

3. Glykogenbestimmung im Muskel.

Das Glykogen von $25 \mathrm{~g}$ Muskel invertirt in $400 \mathrm{ccm}$.

In $81 \mathrm{ccm}$ Zuckerlösung $=5,063 \mathrm{~g}$ Muskel gefunden:

1. $99,0 \mathrm{mg} \mathrm{Cu}_{2} \mathrm{O}$,

2. $98,5 \mathrm{mg} \mathrm{Cu} \mathrm{Cu}_{2} \mathrm{O}$,

$99 \mathrm{mg} \mathrm{Cu}_{2} \mathrm{O}=38,9 \mathrm{mg}$ Zucker $=36,06 \mathrm{mg}$ Glykogen.

In den Muskeln sind 0,7762\% Zucker $=0,7195 \%$ Glykogen.

In der ganzen Muskulatur $=6028 \mathrm{~g}$ Muskeln sind $46,79 \mathrm{~g}$ Zucker $=43,37 \mathrm{~g}$ Glykogen.

4. Glykogenbestimmung in den Knochen.

$1016 \mathrm{~g}$ Knochen gelöst in $3020 \mathrm{cem} 15 \% \mathrm{KOH}$. Das Glykogen von $855 \mathrm{ccm}=287,6 \mathrm{~g}$ Knochen invertirt in $250 \mathrm{ccm}$.

In $81 \mathrm{ccm}$ Zuckerlösung $=93,18 \mathrm{~g}$ Knochen gefunden :

1. $413,5 \mathrm{mg} \mathrm{Cu}_{2} \mathrm{O}$,

2. $412,0 \mathrm{mg} \mathrm{Cu}_{2} \mathrm{O}$.

$413,5 \mathrm{mg} \mathrm{Cu}_{2} \mathrm{O}=183,0 \mathrm{mg}$ Zucker $=170,2 \mathrm{mg}$ Glykogen.

In den Knochen sind 0,197\% Zucker $=0,183 \%$ Glykogen.

In $2032 \mathrm{~g}$ Knochen sind 4,0038 g Zucker $=3,7115 \mathrm{~g}$ Glykogen. 
5. Glykogenbestimmung in den Eingeweiden.

$100 \mathrm{~g}$ Eingeweide gelöst in $400 \mathrm{ccm} 15 \% \mathrm{KOH}$. Das Glykogen von $335 \mathrm{ccm}$ Lösung $=83,6 \mathrm{~g}$ Organ invertirt in $150 \mathrm{ccm}$.

In $70 \mathrm{ccm}$ Zuckerlösung $=39 \mathrm{~g}$ Eingeweide gefunden:

1. $31,0 \mathrm{mg} \mathrm{Cu}_{2} \mathrm{O}$,

2. $28,5 \mathrm{mg} \mathrm{Cu}_{2} \mathrm{O}$.

$31 \mathrm{mg} \mathrm{Cu}_{2} \mathrm{O}=10,3 \mathrm{mg}$ Zucker $=9,55 \mathrm{mg}$ Glykogen.

In den Eingeweiden sind 0,0264\% Zucker $=0,0254 \%$ Glykogen. $1058 \mathrm{~g}$ Eingeweide enthalten $0,2794 \mathrm{~g}$ Zucker $=0,259 \mathrm{~g}$ Glykogen.

6. Glykogenbestimmung im Fell.

Das Glykogen von $25 \mathrm{~g}$ Fell invertirt in $400 \mathrm{ccm}$.

In $81 \mathrm{ccm}$ Zuckerlösung $=5,06 \mathrm{~g}$ Fell gefunden:

1. $57,0 \mathrm{mg} \mathrm{Cu}_{2} \mathrm{O}$,

2. $56,5 \mathrm{mg} \mathrm{Cu}_{2} \mathrm{O}$.

$57 \mathrm{mg} \mathrm{Cu}_{2} \mathrm{O}=20,5 \mathrm{mg}$ Zucker $=19 \mathrm{mg}$ Glykogen.

Im Fell sind $0,4051 \%$ Zucker $=0,3755 \%$ Glykogen.

$2103 \mathrm{~g}$ Fell enthalten 8,5193 $\mathrm{g}$ Zucker $=7,8974 \mathrm{~g}$ Glykogen.

7. Glykogenbestimmung im Herzen.

Das Glykogen von $50,5 \mathrm{~g}$ Herz invertirt in $500 \mathrm{ccm}$.

In $81 \mathrm{ccm}$ Zuckerlösung $=8,101 \mathrm{~g}$ Herz gefunden:

1. $31,0 \mathrm{mg} \mathrm{Cu}_{2} \mathrm{O}$,

2. $28,8 \mathrm{mg} \mathrm{Cu}_{2} \mathrm{O}$.

$31 \mathrm{mg} \mathrm{Cu}_{2} \mathrm{O}$ entsprechen $10,3 \mathrm{mg}$ Zucker $=9,55 \mathrm{mg}$ Glykogen.

Im Herzen sind $0,1272 \%$ Zucker $=0,1179 \%$ Glykogen.

$101 \mathrm{~g}$ Herz enthalten 0,1284 g Zucker $=0,119 \mathrm{~g}$ Glykogen.

8. Glykogenbestimmung im Gehirn.

Das Glykogen von $61 \mathrm{~g}$ Gehirn invertirt in $150 \mathrm{ccm}$. Es wurde das Glykogen auf dem Filter gelöst und die Lösung invertirt.

In $70 \mathrm{ccm}$ Zuckerlösung $=28,47 \mathrm{~g}$ Gehirn gefunden:

1. $40 \mathrm{mg} \mathrm{Cu} \mathrm{Cu}_{2} \mathrm{O}$.

2. $30 \mathrm{mg} \mathrm{Cu}_{2} \mathrm{O}$.

$40 \mathrm{mg} \mathrm{Cu}_{2} \mathrm{O}$ entsprechen $13,35 \mathrm{mg}$ Zucker $=12,38 \mathrm{mg}$ Glykogen.

Im Gehirn sind 0,0469\% Zucker $=0,0435 \%$ Glykogen.

$61 \mathrm{~g}$ Gehirn enthalten $0,0286 \mathrm{~g}$ Zucker $=0,0265 \mathrm{~g}$ Glykogen. 


\section{Versuch II.}

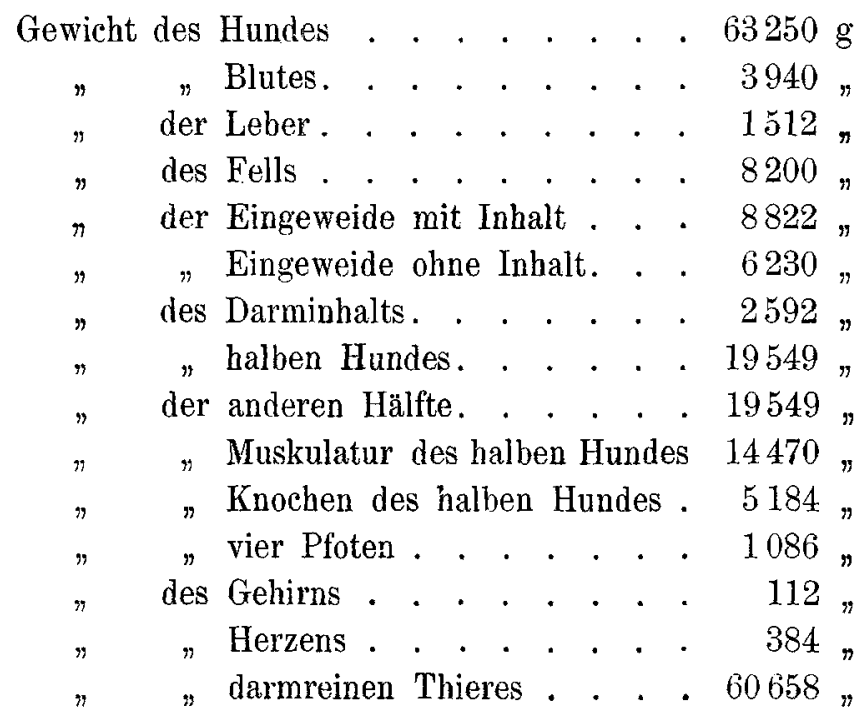

1. Glykogenbestimmung im Blut.

$1800 \mathrm{~g}$ Blut in $2000 \mathrm{ccm} 60 \% \mathrm{KOH}$ aufgefangen und gelöst.

Das Glykogen von $900 \mathrm{~g}$ Blut invertirt in $400 \mathrm{ccm}$.

In $81 \mathrm{ccm}$ Zuckerlösung $=182,25 \mathrm{~g}$ Blut gefunden :

$$
\begin{aligned}
& \text { 1. } 9,5 \mathrm{mg} \mathrm{Cu}_{2} \mathrm{O} \text {, } \\
& \text { 2. } 9,0 \mathrm{mg} \mathrm{Cu}_{2} \mathrm{O} \text {. }
\end{aligned}
$$

$9,5 \mathrm{mg} \mathrm{Cu}_{2} \mathrm{O}$ entsprechen $3 \mathrm{mg}$ Zucker $=2,78 \mathrm{mg}$ Glykogen.

Im Blut sind 0,0016\% Zucker $=0,0015 \%$ Glykogen.

$3940 \mathrm{~g}$ Blut enthalten $0,0640 \mathrm{~g}$ Zucker $=0,0601 \mathrm{~g}$ Glykogen.

2. Glykogenbestimmung in der Leber.

A. Das Glykogen von $25 \mathrm{~g}$ Leber in $1000 \mathrm{cem}$ invertirt.

In 81 ccm Zuckerlösung $=2,025 \mathrm{~g}$ Leber gefunden:

$$
\text { 1. } 259,7 \mathrm{mg} \mathrm{Cu}_{2} \mathrm{O} \text {, }
$$

$259,7 \mathrm{mg} \quad \mathrm{Cu}_{2} \mathrm{O}$ entsprechen 109,3 $\mathrm{mg}$ Zucker $=101,3 \mathrm{mg}$ Glykogen.

In der Leber sind $5,3975 \%$ Zucker $=5,0035 \%$ Glykogen.

B. $100 \mathrm{~g}$ Leber wurden in siedendes Wasser gebracht und vier Stunden lang mit $1000 \mathrm{~cm} \mathrm{~W}^{\top}$ asser im Wasserbade gekocht, die Flüssigkeit abfiltrirt und der Rückstand nochmals mit $500 \mathrm{ccm}$ Wasser zwei Stunden lang gekocht und filtrirt. Die Filtrate wurden ver- 
einigt, mit $100 \mathrm{ccm}$ Salzsäure von 1,19 versetzt, auf $2000 \mathrm{ccm}$ verdünnt und direct invertirt. Der Rückstand wird in $100 \mathrm{cem} 30 \%$ $\mathrm{KOH}$ gelöst und darin auf gewöhnliche Art das Glykogen bestimmt. Volumen der Zuckerlösung $2000 \mathrm{ccm}$.

I. Analyse vom Wasserauszug.

In $81 \mathrm{cem}$ Zuckerlösung $=4,05 \mathrm{~g}$ Leber gefunden:

$$
\begin{aligned}
& \text { 1. } 461,0 \mathrm{mg} \mathrm{Cu} \mathrm{Cu}_{2} \mathrm{O} \text {, } \\
& \text { 2. } 457,5 \mathrm{mg} \mathrm{Cu}_{2} \mathrm{O} \text {. }
\end{aligned}
$$

$461 \mathrm{mg} \mathrm{Cu}_{2} \mathrm{O}$ entsprechen $243,7 \mathrm{mg}$ Zucker $=225,9 \mathrm{mg}$ Glykogen.

In der Leber sind 6,0174\% Zucker $=5,5781 \%$ Glykogen im Wasserauszug.

II. Analyse des Rückstandes.

In $81 \mathrm{ccm}$ Zuckerlösung $=4,05 \mathrm{~g}$ Leber gefunden :

$$
\begin{aligned}
& \text { 1. } 212,5 \mathrm{mg} \mathrm{Cu}_{2} \mathrm{O} \text {, } \\
& \text { 2. } 211,5 \mathrm{mg} \mathrm{Cu}_{2} \mathrm{O} \text {. }
\end{aligned}
$$

212,5 $\mathrm{mg} \mathrm{Cu}_{2} \mathrm{O}$ entsprechen 88,4 $\mathrm{mg}$ Zucker $=81,9 \mathrm{mg}$ Glykogen.

Im Rückstand sind 2,183\% Zucker $=2,024 \%$ Glykogen.

In der Leber sind also im Ganzen 8,1974\% Zucker $=7,6021 \%$ Glykogen.

$1512 \mathrm{~g}$ Leber enthalten also $123,94 \mathrm{~g}$ Zucker $=114,9 \mathrm{~g}$ Glykogen.

3. Glykogenbestimmung im Muskel.

Das Glykogen von $100 \mathrm{~g}$ Muskel invertirt in $1000 \mathrm{ccm}$.

In $81 \mathrm{ccm}$ Zuckerlösung $=8,1 \mathrm{~g}$ Muskel gefunden:

1. $186 \mathrm{mg} \mathrm{Cu}_{2} \mathrm{O}$,

2. $183 \mathrm{mg} \mathrm{Cu} \mathrm{Cu}_{2} \mathrm{O}$.

$186 \mathrm{mg} \mathrm{Cu}_{2} \mathrm{O}$ entsprechen $76,7 \mathrm{mg}$ Zucker $=71,1 \mathrm{mg}$ Glykogen.

In den Muskeln sind 0,9469\% Zucker $=0,8778 \%$ Glykogen.

$28940 \mathrm{~g}$ Muskeln enthalten 274,03 g Zucker $=254,03 \mathrm{~g}$ Glykogen.

4. Glykogenbestimmung in den Knochen.

$6270 \mathrm{~g}$ Knochen gelöst in $8400 \mathrm{ccm} 15 \% \mathrm{KOH}$.

Das Glykogen von $1000 \mathrm{cem}$ Knochenlösung $=746,43 \mathrm{~g}$ Knochen invertirt in $1000 \mathrm{ccm}$.

In $81 \mathrm{ccm}$ Zuckerlösung $=60,46 \mathrm{~g}$ Knochen gefunden :

1. $542 \mathrm{mg} \mathrm{Cu}_{2} \mathrm{O}$,

2. $541 \mathrm{mg} \mathrm{Cu}_{2} \mathrm{O}$. 
Ueber den Maximalwerth des Gesammtglykogengehalts von Hunden.

$542 \mathrm{mg} \mathrm{Cu} \mathrm{Cu}_{2} \mathrm{O}$ entsprechen $256 \mathrm{mg}$ Zucker $=237,3 \mathrm{mg}$ Glykogen. In den Knochen sind 0,4234\% Zucker $=0,3925 \%$ Glykogen. $11454 \mathrm{~g}$ Knochen enthalten $48,49 \mathrm{~g}$ Zucker $=44,96 \mathrm{~g}$ Glykogen.

5. Glykogenbestimmung der Eingeweide.

$500 \mathrm{~g}$ Eingeweide in $2000 \mathrm{ccm} 15 \% \mathrm{KOH}$ gelöst.

Das Glykogen von $250 \mathrm{~g}$ Eingeweide invertirt in $400 \mathrm{ccm}$.

In $81 \mathrm{ccm}$ Zuckerlösung $=50,625 \mathrm{~g}$ Eingeweide gefunden :

$$
\begin{aligned}
& \text { 1. } 104,5 \mathrm{mg} \mathrm{Cu} \mathrm{Cu}_{2} \mathrm{O} \text {, } \\
& \text { 2. } 96 \mathrm{mg} \mathrm{Cu} \mathrm{Cu}_{2} \mathrm{O} \text {. }
\end{aligned}
$$

104,5 $\mathrm{mg} \mathrm{Cu}_{2} \mathrm{O}$ entsprechen $41,1 \mathrm{mg}$ Zucker $=37,9 \mathrm{mg}$ Glykogen.

In den Eingeweiden sind $0,0812 \%$ Zucker $=0,0753 \%$ Glykogen. $6230 \mathrm{~g}$ Eingeweide enthalten 5,0578 g Zucker $=4,6886 \mathrm{~g}$ Glykogen.

6. Glykogenbestimmung im Fell. $2 \times 500$ g Fell in $500 \mathrm{cem} 60 \%$. KOH gelöst.

A. Das Glykogen von $166,67 \mathrm{~g}$ Fell invertirt in $750 \mathrm{ccm}$.

In $81 \mathrm{ccm}$ Zuckerlösung $=18 \mathrm{~g}$ Fell gefunden:

$$
108 \mathrm{mg} \mathrm{Cu}_{2} \mathrm{O} \text {. }
$$

$108 \mathrm{mg} \mathrm{Cu} \mathrm{Cu}_{2} \mathrm{O}$ entsprechen $42,65 \mathrm{mg} \mathrm{Zucker}=39,54 \mathrm{mg}$ Glykogen. Im Fell sind also 0,237\% Zucker $=0,2197 \%$ Glykogen.

B. Das Glykogen von $166,67 \mathrm{~g}$ Fell invertirt in $800 \mathrm{ccm}$.

In $81 \mathrm{ccm}$ Zuckerlösung $=16,875 \mathrm{~g}$ Fell gefunden:

$85,5 \mathrm{mg} \mathrm{Cu} \mathrm{Cu}_{2} \mathrm{O}$.

$85,5 \mathrm{mg} \mathrm{Cu}_{2} \mathrm{O}$ entsprechen $32,8 \mathrm{mg}$ Zucker $=30,4 \mathrm{mg}$ Glykogen.

Im Fell sind 0,19437\% Zucker $=0,1802 \%$ Glykogen.

Im Fell sind also im Mittel 0,2157\% Zucker $=0,1999 \%$ Glykogen.

$8200 \mathrm{~g}$ Fell enthalten also $17,67 \mathrm{~g}$ Zucker $=16,4 \mathrm{~g}$ Glykogen.

7. Glykogenbestimmung im Herzen.

Das Glykogen von $384 \mathrm{~g}$ Herz invertirt in $400 \mathrm{ccm}$.

In $81 \mathrm{ccm}$ Zuckerlösung $=77,76 \mathrm{~g}$ Herz gefunden:

1. $201,5 \mathrm{mg} \mathrm{Cu}_{2} \mathrm{O}$,

2. $197 \mathrm{mg} \mathrm{Cu} \mathrm{Cu}_{2} \mathrm{O}$.

$201,5 \mathrm{mg} \mathrm{Cu}_{2} \mathrm{O}$ entsprechen 83,5 $\mathrm{mg}$ Zucker $=77,3 \mathrm{mg}$ Glykogen. 
Im Herzen sind 0,1074\% Zucker $=0,09954 \%$ Glykogen.

$384 \mathrm{~g}$ Herz enthalten also $0,4124 \mathrm{~g}$ Zucker $=0,3823 \mathrm{~g}$ Glykogen.

8. Glykogenbestimmung im Gehirn.

Das Glykogen von $112 \mathrm{~g}$ Gehirn in $400 \mathrm{ccm}$ invertirt.

In 81 cem Zuckerlösung $=22,68 \mathrm{~g}$ Gehirn gefunden:

1. $138,3 \mathrm{mg} \mathrm{Cu}_{2} \mathrm{O}$,

2. $136 \mathrm{mg} \mathrm{Cu}_{2} \mathrm{O}$.

$138,3 \mathrm{mg} \mathrm{Cu} \mathrm{O}_{2} \mathrm{O}$ entsprechen $55,85 \mathrm{mg}$ Zucker $=51,77 \mathrm{mg}$ Glykogen.

Im Gehirn sind also 0,24625\% Zucker $=0,2283 \%$ Glykogen.

$112 \mathrm{~g}$ Gehirn enthalten $0,2758 \mathrm{~g}$ Zucker $=0,2557 \mathrm{~g}$ Glykogen.

Versuch III.

Gewicht des Hundes . . . . . . . $9700 \mathrm{~g}$

" des darmreinen Hundes . . . . 9507"

$"$ des Blutes . . . . . . . 617 "

$" \quad$ der Leber I . . . . . . $605 "$

" der Leber II . . . . . . . 214 ,

" des Fells . . . . . . . . $1180 "$

" der Eingeweide mit Inhalt . . 1201 "

" der Eingeweide ohne Inhalt . . 1008 "

" des Darminhalts . . . . . . 193 "

" des halben Hundes . . . . . 2662 "

" der anderen Hälfte . . . . 2762"

" des Gehirns . . . . . . . . $80 "$

"des Herzens . . . . . . . 70"

" der Muskulatur des halben Hundes 1757 "

" der Knochen des halben Hundes . 978 "

1. Glykogenbestimmung in der Leber.

A. Analyse von Leberstück I. Das Glykogen von $25 \mathrm{~g}$ Leber invertirt in $2000 \mathrm{ccm}$.

I. Glykogenfällung sofort abfiltrirt.

In $81 \mathrm{ccm}$ Zuckerlösung $=1,0125 \mathrm{~g}$ Leber gefunden:

1. $457,5 \mathrm{mg} \mathrm{Cu}_{2} \mathrm{O}$,

2. $456 \mathrm{mg} \mathrm{Cu}_{2} \mathrm{O}$.

II. Glykogenfällung nach dreiwöchentlichem Stehen abfiltrirt.

In $81 \mathrm{ccm}$ Zuckerlösung $=1,0125 \mathrm{~g}$ Leber gefunden: 


$$
\begin{aligned}
& \text { 1. } 459,5 \mathrm{mg} \mathrm{Cu}_{2} \mathrm{O} \text {, } \\
& \text { 2. } 457,5 \mathrm{mg} \mathrm{Cu}_{2} \mathrm{O} \text {. }
\end{aligned}
$$

$459,5 \mathrm{mg} \mathrm{Cu}_{2} \mathrm{O}$ entsprechen 208,6 mg Zucker. Die Titration des

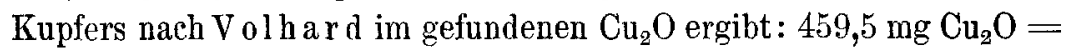
$402,9 \mathrm{mg} \mathrm{Cu}=205,3 \mathrm{mg}$ Zucker $=190,3 \mathrm{mg}$ Glykogen.

In Leberstück I sind also $20,276 \%$ Zucker $=18,815 \%$ Glykogen.

In $605 \mathrm{~g}$ Leber I sind also $122,67 \mathrm{~g}$ Zucker $=113,84 \mathrm{~g}$ Glykogen.

B. Analyse von Leberstück II. Das Glykogen von 25 g Leber invertirt in $2000 \mathrm{ccm}$.

In 81 ccm Zuckerlösung $=1,0125 \mathrm{~g}$ Leber gefunden:

$$
\text { 1. } 450 \mathrm{mg} \mathrm{Cu}_{2} \mathrm{O} \text {, }
$$

$450 \mathrm{mg} \mathrm{Cu} \mathrm{Cu}_{2} \mathrm{O}$ entsprechen 203,2 mg Zucker. Die Titration des $\mathrm{Cu}$ nach Volhard ergibt:

$$
\begin{aligned}
& 450 \mathrm{mg} \mathrm{Cu}_{2} \mathrm{O}=397,98 \mathrm{mg} \mathrm{Cu}, \\
& 449,5 \mathrm{mg} \mathrm{Cu}_{2} \mathrm{O}=395,21 \mathrm{mg} \mathrm{Cu} .
\end{aligned}
$$

Im Mittel sind in $81 \mathrm{ccm}$ gefunden: $396,6 \mathrm{mg} \mathrm{Cu}=201,3 \mathrm{mg}$ Zucker $=186,6 \mathrm{mg}$ Glykogen.

In Leberstück II sind also $19,88 \%$ Zucker $=18,33 \%$ Glykogen.

$214 \mathrm{~g}$ Leber II enthalten 42,54 g Zucker $=39,22 \mathrm{~g}$ Glykogen.

In der ganzen Leber sind also enthalten: $20,17 \%$ Zucker $=$ 18,69\% Glykogen. $819 \mathrm{~g}$ Leber enthalten 165,21 g Zucker $=$ 153,07 g Glykogen.

2. Glykogenbestimmung im Muskel.

Das Glykogen von $25 \mathrm{~g}$ Muskel invertirt in $1000 \mathrm{ccm}$.

A. Glykogenfällung sofort abfiltrirt.

In $81 \mathrm{cem}$ Zuckerlösung $=2,025 \mathrm{~g}$ Muskel gefunden :

$$
\begin{aligned}
& \text { 1. } 136,5 \mathrm{mg} \mathrm{Cu}_{2} \mathrm{O} \\
& \text { 2. } 132 \mathrm{mg} \mathrm{Cu}_{2} \mathrm{O} \text {. }
\end{aligned}
$$

B. Glykogenfällung nach drei Wochen abfiltrirt. Gefunden in $81 \mathrm{ccm}$ Zuckerlösung:

$$
\begin{aligned}
& 138,5 \mathrm{mg} \mathrm{Cu}_{2} \mathrm{O}=56 \mathrm{mg} \text { Zucker, } \\
& 136,8 \mathrm{mg} \mathrm{Cu}_{2} \mathrm{O} .
\end{aligned}
$$

$138,5 \mathrm{mg} \mathrm{Cu} \mathrm{Cu}_{2} \mathrm{O}=121,98 \mathrm{mg} \mathrm{Cu}=55,5 \mathrm{mg}$ Zucker $=51,4 \mathrm{mg}$ Glykogen. 
Im Muskel sind 2,7407\% Zucker $=2,546 \%$ Glykogen.

In $3514 \mathrm{~g}$ Muskel sind $96,32 \mathrm{~g}$ Zucker $=89,27 \mathrm{~g}$ Glykogen.

3. Glykogenbestimmung in den Knochen.

$978 \mathrm{~g}$ Knochen gelöst in $2800 \mathrm{ccm} 15 \% \mathrm{KOH}$. Das Glykogen von $1000 \mathrm{ccm}$ Knochenlösung $=349,28 \mathrm{~g}$ Knochen invertirt in $2000 \mathrm{ccm}$.

In 81 cem Zuckerlösung $=14,15 \mathrm{~g}$ Knochen gefunden:

1. $366 \mathrm{mg} \mathrm{Cu}_{2} \mathrm{O}=159,1 \mathrm{mg}$ Zucker,

2. $365 \mathrm{mg} \mathrm{Cu}_{2} \mathrm{O}$.

$366 \mathrm{mg} \mathrm{Cu} 2 \mathrm{O}=317,7 \mathrm{mg} \mathrm{Cu}=155 \mathrm{mg}$ Zucker $=143,7 \mathrm{mg}$ Glykogen.

In den Knochen sind also 1,0958\% Zucker $=0,9963 \%$ Glykogen. $1956 \mathrm{~g}$ Knochen enthalten also : 21,44 g Zucker $=19,48 \mathrm{~g}$ Glykogen.

4. Glykogenbestimmung in den Eingeweiden:

Das Glykogen von $475 \mathrm{~g}$ Eingeweide invertirt in $2000 \mathrm{ccm}$.

In $40,5 \mathrm{ccm}$ Zuckerlösung $=9,619 \mathrm{~g}$ Eingeweide gefunden:

1. $313 \mathrm{mg} \mathrm{Cu} \mathrm{Cu}_{2} \mathrm{O}=133,4 \mathrm{mg}$ Zucker,

2. $312,5 \mathrm{mg} \mathrm{Cu} \mathrm{Cu}_{2} \mathrm{O}$.

$313 \mathrm{mg} \mathrm{Cu}_{2} \mathrm{O}=275,1 \mathrm{mg} \mathrm{Cu}=132 \mathrm{mg}$ Zucker $=121,4 \mathrm{mg}$ Glykogen.

Die Eingeweide enthalten also:

$1,5829 \%$ Zucker $=1,4674 \mathrm{~g}$ Glykogen.

$1008 \mathrm{~g}$ Eingeweide enthalten:

$15,98 \mathrm{~g}$ Zucker $=14,89 \mathrm{~g}$ Glykogen.

5. Glykogenbestimmung im Fell.

$597 \mathrm{~g}$ Fell $+600 \mathrm{ccm} 60 \% \mathrm{KOH}$ verdünnt auf $2400 \mathrm{ccm}$.

$2 \times 600$ cem Felllösung $=149,25 \mathrm{~g}$ Fell gefällt.

A. Glykogenfällung sofort in Arbeit genommen. Gefunden in $81 \mathrm{ccm}=12,09 \mathrm{~g}$ Fell : $233 \mathrm{mg} \mathrm{Cu}_{2} \mathrm{O}$.

B. GJykogenfällung nach drei Wochen in Arbeit genommen. Gefunden in $81 \mathrm{ccm}=12,09 \mathrm{~g}$ Fell:

1. $240,5 \mathrm{mg} \mathrm{Cu}_{2} \mathrm{O}=100,5 \mathrm{mg}$ Zucker,

2. $238 \mathrm{mg} \mathrm{Cu}_{2} \mathrm{O}$.

$240,5 \mathrm{mg} \mathrm{Cu}_{2} \mathrm{O}$ sind $=201,9 \mathrm{mg} \mathrm{Cu}=94,7 \mathrm{mg}$ Zucker $=87,8 \mathrm{mg}$ Glykogen. 
Im Fell sind also 0,7833\% Zucker $=0,726 \%$ Glykogen.

$1180 \mathrm{~g}$ Fell enthalten demnach:

$9,29 \mathrm{~g}$ Zucker $=8,57 \mathrm{~g}$ Glykogen.

6. Glykogenbestimmung im Herzen.

Das Glykogen von $70 \mathrm{~g}$ Herz invertirt in $300 \mathrm{~cm}$.

In $81 \mathrm{ccm}$ Zuckerlösung $=18,9 \mathrm{~g}$ Herz gefunden :

1. $282 \mathrm{mg} \mathrm{Cu}_{2} \mathrm{O}=119,3 \mathrm{mg}$ Zucker,

2. $281 \mathrm{mg} \mathrm{Cu}_{2} \mathrm{O}$,

3. $280,5 \mathrm{mg} \mathrm{Cu}_{\mathrm{g}} \mathrm{O}$.

$282 \mathrm{mg} \mathrm{Cu}_{2} \mathrm{O}$ sind $=248,4 \mathrm{mg} \mathrm{Cu}=118,2 \mathrm{mg}$ Zucker $=104, \check{\mathrm{mg}}$ Gly kogen.

Im Herzen sind also 0,6247\% Zucker $=0,5791 \%$ Glykogen.

In $70 \mathrm{~g}$ Herz sind demnach $0,4373 \mathrm{~g}$ Zucker $=0,4054 \mathrm{~g}$ Glykogen.

7. Bestimmung des Glykogens im Gehirn.

Das Glykogen von $80 \mathrm{~g}$ Gehirn invertirt in $500 \mathrm{ccm}$.

In 81 ccm Zuckerlösung $=12,96 \mathrm{~g}$ Gehirn gefunden :

1. $95,5 \mathrm{mg} \mathrm{Cu}_{2} \mathrm{O}$,

2. $93 \mathrm{mg} \mathrm{Cu} 2$.

95,5 $\mathrm{mg} \mathrm{Cu}_{2} \mathrm{O}=0,0372 \mathrm{mg}$ Zucker $=0,0344 \mathrm{mg}$ Glykogen.

Im Gehirn sind $0,2828 \%$ Zucker $=0,2621 \%$ Glykogen.

In $80 \mathrm{~g}$ Gehirn sind demnach $0,2262 \mathrm{~g}$ Zucker $=0,2097 \mathrm{~g}$ Glykogen.

Versuch IV.

Gewicht des Hundes . . . . . . $7350 \mathrm{~g}$

darmreinen Hundes. . . 7232 "

"Blutes . . . . . . . 369 "

der Leber . . . . . . 909 "

". Eingeweide mit Inbalt. . . 897 "

$"$ ohne "... . 779 "

des Darminhalts . . . . . . 118 "

"Gehirns . . . . . . . 72 "

"Herzens . . . . . . . . 48 "

"Fells . . . . . . . . 813 "

" halben Hundes . . . . . 2029 "

der anderen Hälfte . . . . . 1972 "

"Muskulatur des halben Hundes 1228 "

"Knochen des halben Hundes . 760 " 
1. Glykogenbestimmung der Leber.

Das Glykogen von $12,5 \mathrm{~g}$ Leber invertirt in $1000 \mathrm{ccm}$.

A. Glykogenfällung sofort in Arbeit genommen.

Gefunden in $81 \mathrm{ccm}$ Zuckerlösung $=1,0125 \mathrm{~g}$ Leber:

$$
\begin{aligned}
& \text { 1. } 428,5 \mathrm{mg} \mathrm{Cu}_{2} \mathrm{O} \text {, } \\
& \text { 2. } 425,3 \mathrm{mg} \mathrm{Cu}_{2} \mathrm{O} \text {. }
\end{aligned}
$$

B. Glykogenfällung nach drei Wochen verarbeitet.

Gefunden in $81 \mathrm{cem}$ Zuckerlösung $=1,0125 \mathrm{~g}$ Leber:

1. $424,5 \mathrm{mg} \mathrm{Cu}_{2} \mathrm{O}=189,45 \mathrm{mg}$ Zucker,

2. $424,5 \mathrm{mg} \mathrm{Cu} \mathrm{Cu}_{2} \mathrm{O}$.

$424,5 \mathrm{mg} \mathrm{Cu}_{2} \mathrm{O}=372,4 \mathrm{mg} \mathrm{Cu}=186,7 \mathrm{mg}$ Zucker $=173,1 \mathrm{mg}$ Glykogen.

In der Leber sind also 18,44\% Zucker $=17,096 \%$ Glykogen. $909 \mathrm{~g}$ Leber enthalten $167,64 \mathrm{~g}$ Zucker $=155,4 \mathrm{~g}$ Glykogen.

2. Glykogenbestimmung in den Muskeln.

$2 \times 100 \mathrm{~g}$ Muskel in $60 \% \mathrm{KOH}$ aufgelöst. Das Glykogen von $25 \mathrm{~g}$ Muskel in $500 \mathrm{ccm}$ invertirt.

Gefunden in $81 \mathrm{ccm}$ Zuckerlösung $=4,05 \mathrm{~g}$ Muskel:
A. 1. $341,5 \mathrm{mg}^{\circ} \mathrm{Cu}_{2} \mathrm{O}=147 \mathrm{mg}$ Zucker,
2. $341 \mathrm{mg} \mathrm{Cu} \mathrm{Cu}_{2} \mathrm{O}$.
B. $1.320 \mathrm{mg} \mathrm{Cu} \mathrm{Cu}_{2} \mathrm{O}=137 \mathrm{mg}$ Zucker,
2. $320 \mathrm{mg} \mathrm{Cl}_{2} \mathrm{O}$.

A. $341,5 \mathrm{mg} \mathrm{Cu}_{2} \mathrm{O}=302,1 \mathrm{mg} \mathrm{Cu}=146,4 \mathrm{mg}$ Zucker $=135,9 \mathrm{mg}$ Glykogen.

In den Muskeln sind 3,6148\% Zucker $=3,3509 \%$ Glykogen.

B. $320 \mathrm{mg} \mathrm{Cu}_{2} \mathrm{O}=282,7 \mathrm{mg} \mathrm{Cu}=136,1 \mathrm{mg}$ Zucker $=126,9 \mathrm{mg}$ Glykogen.

In den Muskeln sind also 3,3605\% Zucker $=3,1152 \%$ Glykogen.

Im Mittel sind also in der Muskulatur 3,4876\% Zucker $=3,233 \%$ Glykogen.

$2456 \mathrm{~g}$ Muskel enthalten demnach $85,66 \mathrm{~g}$ Zucker $=79,42 \mathrm{~g}$ Glykogen. 
Ueber den Maximalwerth des Gesammtglykogengehalts von Hunden. 233

3. Glykogenbestimmung in ren Knochen.

$760 \mathrm{~g}$ Knochen gelöst in 2400 cem $15^{\circ} \% \mathrm{KOH}$. Das Glykogen von $200 \mathrm{ccm}$ Knochenlösung $=63,33 \mathrm{~g}$ Knochen invertirt in $500 \mathrm{ccm}$.

Gefunden in 81 ccm Zuckerlösung $=10,26$ Knochen:

1. $366,5 \mathrm{mg} \mathrm{Cu}_{2} \mathrm{O}=159,4 \mathrm{mg}$ Zucker,

2. $365,5 \mathrm{mg} \mathrm{Cu} \mathrm{Cu}_{2} \mathrm{O}$.

$366,5 \mathrm{mg} \mathrm{Cu}_{2} \mathrm{O}=324,4 \mathrm{mg} \mathrm{Cu}=158,8 \mathrm{mg}$ Zucker $=147,2 \mathrm{mg}$ Glykogen.

In den Knochen sind 1,4163\% Zucker $=1,3129 \%$ Glykogen. $1520 \mathrm{~g}$ Knochen enthalten $21,52 \mathrm{~g}$ Zucker $=19,96 \mathrm{~g}$ Glykogen.

4. Glykogenbestimmung in den Eingeweiden.

$725 \mathrm{~g}$. Eingeweide gelöst in $2900 \mathrm{ccm} 15 \% \mathrm{KOH}$. Das Glykogen von $300 \mathrm{ccm}$ Eingeweidelösung invertirt in $500 \mathrm{ccm}$.

Gefunden in 81 ccm Zuckerlösung $=12,15 \mathrm{~g}$ Eingeweide:

1. $458,8 \mathrm{mg} \mathrm{Cu}_{2} \mathrm{O}=208,2 \mathrm{mg}$ Zucker,

2. $457,5 \mathrm{mg} \mathrm{Cu}_{2} \mathrm{O}$.

$458,8 \mathrm{mg} \mathrm{Cu} \mathrm{Cu}_{2} \mathrm{O}=402,3 \mathrm{mg} \mathrm{Cu}=205 \mathrm{mg}$ Zucker $=190 \mathrm{mg}$ Glykogen.

In den Fingeweiden sind 1,6328\% Zucker $=1,5141 \%$ Glykogen. $779 \mathrm{~g}$ Eingeweide enthalten demnach:

$12,72 \mathrm{~g}$ Zucker $==11,795 \mathrm{~g}$ Glykogen.

5. Glykogenbestimmung im Fell.

$811 \mathrm{~g}$ Fell gelöst in $3200 \mathrm{ccm} 15 \% \mathrm{KOH}$. Das Glykogen aus $400 \mathrm{cem}$ Felllösung invertirt in $500 \mathrm{ccm}$.

Gefunden in 81 cem Zuckerlösung $=16,42 \mathrm{~g}$ Fell:

1. $347,5 \mathrm{mg} \mathrm{Cu}_{2} \mathrm{O}=149,9 \mathrm{mg}$ Zucker,

2. $346,4 \mathrm{mg} \mathrm{Cu} \mathrm{Cu}_{2} \mathrm{O}$.

$347,5 \mathrm{mg} \mathrm{Cu}_{2} \mathrm{O}=306,3 \mathrm{mg} \mathrm{Cu}=148,64 \mathrm{mg}$ Zucker $=137,8 \mathrm{mg}$ Glykogen.

Im Fell sind also 0,9051\% Zucker $=0,839 \%$ Glykogen. $811 \mathrm{~g}$ Fell enthalten demnach:

7,34 g Zucker $=6,804 \mathrm{~g}$ Glykogen.

6. Glykogenbestimmung im Herzen.

Das Glykogen von $48 \mathrm{~g}$ Herz invertirt in $300 \mathrm{ccm}$.

Gefunden in 81 cem Zuckerlösung $=12,96 \mathrm{~g}$ Herz: 
1. $239,1 \mathrm{mg} \mathrm{Cu}_{2} \mathrm{O}=100 \mathrm{mg}$ Zucker,

2. $235,5 \mathrm{mg} \mathrm{Cu}_{2} \mathrm{O}$.

$239,1 \mathrm{mg} \mathrm{Cu}_{2} \mathrm{O}=212,4 \mathrm{mg} \mathrm{Cu}=100 \mathrm{mg}$ Zucker $=92,7 \mathrm{mg}$ Glykogen.

Im Herzen sind also 0,7716\% Zucker $=0,7153 \%$ Glykogen. $48 \mathrm{~g}$ Herz enthalten:

$0,3704 \mathrm{~g}$ Zucker $==0,3433 \mathrm{~g}$ Glykogen.

7. Glykogenbestimmung im Gehirn.

Das Glykogen von $72 \mathrm{~g}$ Gehirn invertirt in $400 \mathrm{ccm}$.

Gefunden in $81 \mathrm{ccm}$ Zuckerlösung $=14,58 \mathrm{~g}$ Gehirn:

1. $100,8 \mathrm{mg} \mathrm{Cu}_{2} \mathrm{O}=39,5 \mathrm{mg}$ Zucker,

2. $98,2 \mathrm{mg} \mathrm{Cu}_{2} \mathrm{O}$.

$100,8 \mathrm{mg} \quad \mathrm{Cu}_{2} \mathrm{O}=81,8 \mathrm{mg} \mathrm{Cu}=35,7 \mathrm{mg}$ Zucker $=33,1 \mathrm{mg}$ Glykogen.

Im Gehirn sind also 0,2449\% Zucker $=0,227 \%$ Glykogen.

$72 \mathrm{~g}$ Gehirn enthalten demnach $0,1763 \mathrm{~g}$ Zucker $=0,1634 \mathrm{~g}$ Glykogen.

$$
\text { Versuch V. }
$$

Gewicht des Hundes . . . . . . . . $9200 \mathrm{~g}$

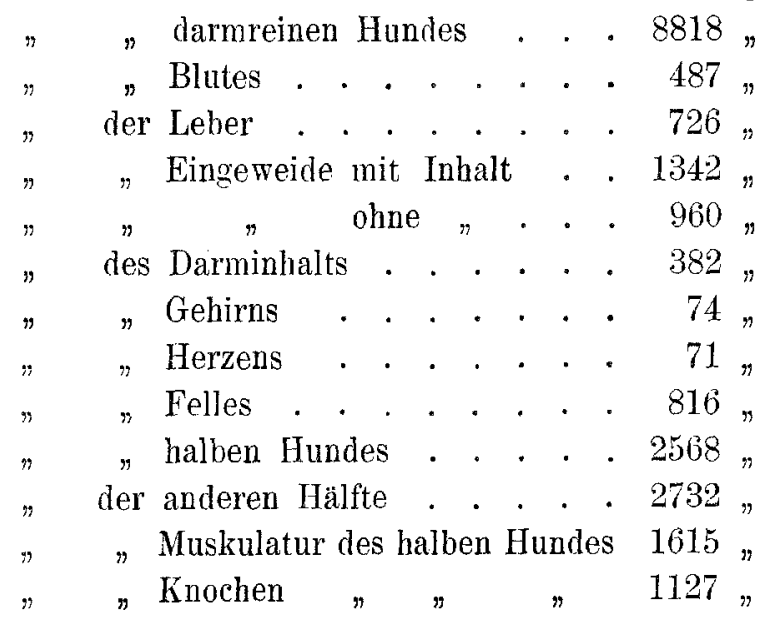

1. Glykogenbestimmung im Blute.

Das Glykogen von $337 \mathrm{~g}$ Blut invertirt in $400 \mathrm{ccm}$.

Gefunden in $81 \mathrm{ccm}$ Zuckerlösung $=68,24 \mathrm{~g}$ Blut.

1. $13,5 \mathrm{mg} \mathrm{Cu} \mathrm{Cu}_{2} \mathrm{O}$

2. $10,8 \mathrm{mg} \mathrm{Cu}_{2} \mathrm{O}$. 
Ueber den Maximalwerth des Gesammtglykogengehalts von Hunden. 235

$13,5 \mathrm{mg} \mathrm{Cu}_{2} \mathrm{O}=4,5 \mathrm{mg}$ Zucker $=4,2 \mathrm{mg}$ Glykogen.

Im Blute sind $0,0066 \%$ Zucker $=0,0061 \%$ Glykogen.

In $487 \mathrm{~g}$ Blut sind demnach $0,032 \mathrm{~g}$ Zucker $=0,0297$ Glykogen.

2. Glykogenbestimmug in der Leber.

Das Glykogen von $12,5 \mathrm{~g}$ Leber in $1000 \mathrm{ccm}$ invertirt.

A. Glykogenfällung sofort verarbeitet.

Gefunden in $81 \mathrm{ccm}$ Zuckerlösung $=1,0125 \mathrm{~g}$ Leber.

1. $409,5 \mathrm{mg} \mathrm{Cu}_{2} \mathrm{O}$,

Im Mittel 406,85 $\mathrm{mg} \mathrm{Cu}_{2} \mathrm{O}$.

B. Glykogenfällung nach drei Wochen verarbeitet.

Gefunden in $81 \mathrm{ccm}$ Zuckerlösung $=1,0125 \mathrm{~g}$ Leber:

1. $406 \mathrm{mg} \mathrm{Cu}_{2} \mathrm{O}=179,6 \mathrm{mg}$ Zucker,

2. $405,5 \mathrm{mg} \mathrm{Cu}_{2} \mathrm{O}$.

$406 \mathrm{mg} \mathrm{Cu}_{2} \mathrm{O}=357,1 \mathrm{mg} \mathrm{Cu}=177,6 \mathrm{mg}$ Zucker $=164,6 \mathrm{mg}$ Glykogen.

In der Leber sind also 17,664\% Zucker $=16,375 \%$ Glykogen.

$726 \mathrm{~g}$ Leber enthalten demnach 128,24 $\mathrm{g}$ Zucker $=118,88 \mathrm{~g}$ Glykogen.

3. Glykogenbestimmung im Muskel.

Das Glykogen von $25 \mathrm{~g}$ Muskel in $500 \mathrm{ccm}$ invertirt.

Gefunden in $81 \mathrm{ccm}$ Zuckerlösung $=4,05 \mathrm{~g}$ Muskel:

1. $375,5 \mathrm{mg} \mathrm{Cu}_{2} \mathrm{O}=164 \mathrm{mg}$ Zucker,

2. $375,0 \mathrm{mg} \mathrm{Cu}_{2} \mathrm{O}$.

$375,5 \mathrm{mg} \mathrm{Cu}_{2} \mathrm{O}=331 \mathrm{mg} \mathrm{Cu}=162,6 \mathrm{mg}$ Zucker $=150,7 \mathrm{mg}$ Glykogen.

In den Muskeln sind also 4,0148\% Zucker $=3,7217 \%$ Glykogen.

$3230 \mathrm{~g}$ Muskeln enthalten demnach 129,28 Zucker $=120,13 \mathrm{~g}$ Glykogen.

4. Glykogenbestimmung in den Knochen.

$1127 \mathrm{~g}$ Knochen $=3200 \mathrm{ccm} 15 \% \mathrm{KOH}$. Das Glykogen vou $200 \mathrm{ccm}$ Knochenlösung $=70,44 \mathrm{~g}$ Knochen invertirt in $500 \mathrm{ccm}$.

Gefunden in $81 \mathrm{ccm}$ Zuckerlösung $=11,41 \mathrm{~g}$ Knochen:

1. $483 \mathrm{mg} \mathrm{Cu}_{2} \mathrm{O}=221 \mathrm{mg}$ Zucker,

2. $482 \mathrm{mg} \mathrm{Cu}_{2} \mathrm{O}$.

$483 \mathrm{mg} \mathrm{Cu}_{2} \mathrm{O}=421,4 \mathrm{mg} \mathrm{Cu}=217,1 \mathrm{mg}$ Zucker $=201,3 \mathrm{mg}$ Glykogen. 
In den Knochen sind also 1,9024\% Zucker $=1,7635 \%$ Glykogen. $2254 \mathrm{~g}$ Knochen enthalten demnach 42,88 $\mathrm{g}$ Zucker $=39,76 \mathrm{~g}$ Glykogen.

5. Glykogenbestimmung in den Eingeweiden.

$835 \mathrm{~g}$ Eingeweide gelöst in $3200 \mathrm{ccm} \mathrm{KOH}$. Das Glykogen von $300 \mathrm{ccm}$ Eingeweidelösung $=78,28 \mathrm{~g}$ Eingeweide invertirt in $500 \mathrm{cem}$.

Gefunden in $81 \mathrm{ccm}$ Zuckerlösung $=10,68 \mathrm{~g}$ Eingeweide:

1. $514,5 \mathrm{mg} \mathrm{Cu} \mathrm{Cu}_{2} \mathrm{O}=240,7 \mathrm{mg}$ Zucker,

2. $514,5 \mathrm{mg} \mathrm{Cu}_{2} \mathrm{O}$.

$514,5 \mathrm{mg} \quad \mathrm{Cu}_{2} \mathrm{O}=449,7 \mathrm{mg} \mathrm{Cu}=235,9 \mathrm{~m} \mathrm{Zucker}=218,7 \mathrm{mg}$ Glykogen.

In den Eingeweiden sind also 1,8428\% Zucker $=1,7162 \%$ Glykogen.

In $960 \mathrm{~g}$ Eingeweide sind demnach $17,69 \mathrm{~g}$ Zucker $=16,4 \mathrm{~g}$ Glykogen.

6. Glykogenbestimmung im Fell.

$808 \mathrm{~g}$ Fell gelöst in $3200 \mathrm{cem} 15 \% \mathrm{KOH}$. Das Glykagen von $300 \mathrm{ccm}$ Felllösung invertirt in $500 \mathrm{cem}$.

Gefunden in $81 \mathrm{ccm}$ Zuckerlösung $=12,19 \mathrm{~g}$ Fell:

1. $457,5 \mathrm{mg} \mathrm{Cu}_{2} \mathrm{O}=207,4 \mathrm{mg}$ Zucker,

2. $457,5 \mathrm{mg} \mathrm{Cu}_{2} \mathrm{O}$.

$457,5 \mathrm{mg} \mathrm{Cu}_{2} \mathrm{O}=401,6 \mathrm{mg} \mathrm{Cu}=204,5 \mathrm{mg}$ Zucker $=189,6 \mathrm{mg}$ Glykogen.

Im Fell sind 1,6801 \% Zucker $=1, \check{0} 974 \%$ Glykogen.

$803 \mathrm{~g}$ Fell enthalten demnach 13,41 $\mathrm{g}$ Zucker $=12,38 \mathrm{~g}$ Glykogen.

7. Glykogenbestimmung im Herzen.

Das Glykogen von $71 \mathrm{~g}$ Herz invertirt in $400 \mathrm{ccm}$.

In $81 \mathrm{ccm}$ Zuckerlösung $=14,38 \mathrm{~g}$ Herz gefunden:

1. $425,5 \mathrm{mg} \mathrm{Cu}_{2} \mathrm{O}=190 \mathrm{mg}$ Zucker,

2. $424 \mathrm{mg} \mathrm{Cu}_{2} \mathrm{O}$.

$425,5 \mathrm{mg} \mathrm{Cu} \mathrm{Cu}_{2} \mathrm{O}=373,3 \mathrm{mg} \mathrm{Cu}=187,25 \mathrm{mg}$ Zucker $=173,6 \mathrm{mg}$ Glykogen.

Im Herzen sind also $1,3204 \% \mathrm{~g}$ Zucker $=1,2073 \%$ Glykogen.

$71 \mathrm{~g}$ Herz enthalten demnach 0,9247 Zucker $=0,8572 \mathrm{~g}$ Glykogen. 
Ueber den Maximalwerth des Gesammtglykogengehalts von Hunden. 237

8. Glykogenbestimmung im Gehirn.

Das Glykogen von $74 \mathrm{~g}$ Gehirn invertirt in $400 \mathrm{ccm}$.

In $81 \mathrm{ccm}$ Zuckerlösung $=14,985 \mathrm{~g}$ Gehirn gefunden :

1. $91 \mathrm{mg} \mathrm{Cu}_{2} \mathrm{O}=35,25 \mathrm{mg}$ Zucker,

2. $89,5 \mathrm{mg} \mathrm{Cu}_{2} \mathrm{O}$.

$91 \mathrm{mg} \mathrm{Cu}_{2} \mathrm{O}$ titrirt nach $\mathrm{Volh}_{\mathrm{ol}} \mathrm{had}=73,8 \mathrm{mg} \mathrm{Cu}=31,75 \mathrm{mg}$ Zucker $=29,4 \mathrm{mg}$ Glykogen.

Im Gehirn sind also 0,2119\% Zucker $=0,1964 \%$ Glykogen.

$74 \mathrm{~g}$ Gehirn enthalten $0,1568 \mathrm{~g}$ Zucker $=0,1454 \mathrm{~g}$ Glykogen.

Versuch VI.

Gewicht des Hundes . . . . . . $8600 \mathrm{~g}$

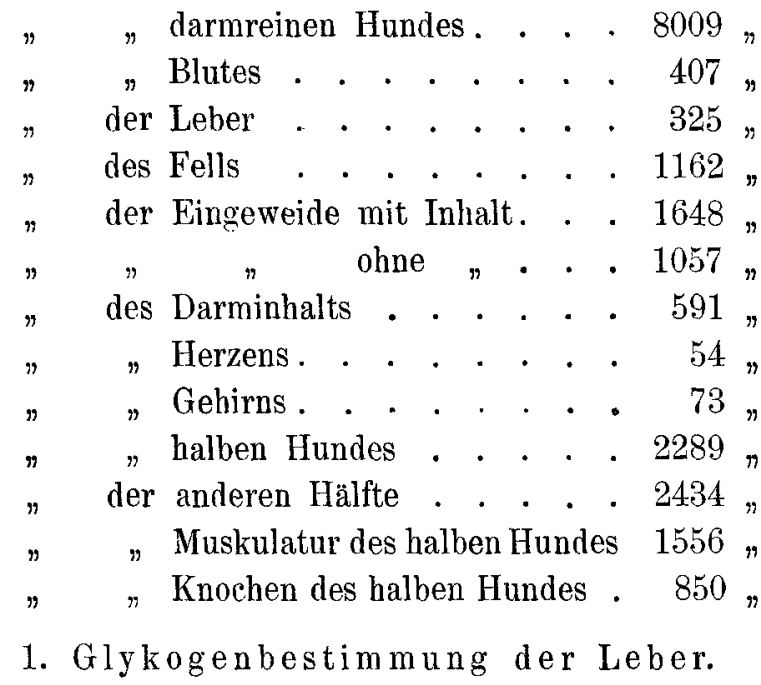

Das Glykogen von $25 \mathrm{~g}$ Leber irvertirt in $1000 \mathrm{ccm}$.

Gefunden in $81 \mathrm{ccm}$ Zuckerlösung $=2,025 \mathrm{~g}$ Leber:

1. $479,5 \mathrm{mg} \mathrm{Cu}_{2} \mathrm{O}=219,75 \mathrm{mg}$ Zucker,

2. $478 \mathrm{mg} \mathrm{Cu}_{2} \mathrm{O}$.

$479,5 \mathrm{mg} \quad \mathrm{Cu}_{2} \mathrm{O}$ enthalten titrirt nach $\mathrm{Volhard} 419,8 \mathrm{mg} \mathrm{Cu}$ $=216 \mathrm{mg}$ Zucker $=200,23 \mathrm{mg}$ Glykogen.

In der Leber sind also 10,607\% Zucker $=9,887 \%$ Glykogen.

$325 \mathrm{~g}$ Leber enthalten $34,664 \mathrm{~g}$ Zucker $=32,134 \mathrm{~g}$ Glykogen.

2. Glykogenbestimmung der Muskeln.

Das Glykogen von $25 \mathrm{~g}$ Muskeln invertirt in $500 \mathrm{ccm}$.

In $81 \mathrm{ccm}$ Zuckerlösung $=4,05 \mathrm{~g}$ Muskel gefunden : 
1. $263 \mathrm{mg} \mathrm{Cu}_{2} \mathrm{O}=110,8 \mathrm{mg}$ Zucker,

2. $262,5 \mathrm{mg} \mathrm{Cu}_{2} \mathrm{O}$.

$263 \mathrm{mg} \mathrm{Cu}_{2} \mathrm{O}=232,8 \mathrm{mg} \mathrm{Cu}(\mathrm{Volhard})=110,4 \mathrm{mg}$ Zucker $=102,34 \mathrm{mg}$ Glykogen.

Im Muskel sind also 2,726\% Zucker $=2,529 \%$ Glykogen.

In $3112 \mathrm{~g}$ Muskeln sind also $84,89 \mathrm{~g}$ Zucker $=78,698 \mathrm{~g}$ Gly kogen.

3. Glykogenbestimmung der Knochen.

$850 \mathrm{~g}$ Knochen in $2500 \mathrm{ccm} 15 \% \mathrm{KOH}$ gelöst.

Das Glykogen von $1000 \mathrm{ccm}$ Knochenlösung in $2000 \mathrm{ccm}$ invertirt. Das Glykogen wurde in diesem Falle nicht auf dem Filter gelöst, so dass die Glykogenlösung filtrirte, sondern das Glykogen wurde vom Filter in eine Glasschale gebracht, das Filter abgespritzt und ausgekocht und der ganze Glykogenniederschlag in der Schale auf dem Wasserbade gelöst. Diese Lösung wurde, ohne vorher filtrirt zu werden, in einen 2-Literkolben gebracht und nach Zusatz von $100 \mathrm{cem}$ Salzsäure vom spec. Gew. 1,19 invertirt.

In $81 \mathrm{ccm}$ Zuckerlösung $=13,77 \mathrm{~g}$ Knochen gefunden:

1. $369,5 \mathrm{mg} \mathrm{Cu}_{2} \mathrm{O}=161 \mathrm{mg}$ Zucker,

2. $369,3 \mathrm{mg} \mathrm{Cu}_{2} \mathrm{O}$.

Die Titration des Kupfers nach Volhard ergab:

$369,5 \mathrm{mg} \mathrm{Cu}{ }_{2} \mathrm{O}=298,6 \mathrm{mg} \mathrm{Cu}=144,55 \mathrm{mgZucker}=134,1 \mathrm{mg}$ Glykogen.

In den Knochen sind also $1,0485 \%$ Zucker $=0,9729 \%$.

In $1700 \mathrm{~g}$ Knochen sind demnach $17,85 \mathrm{~g}$ Zucker $=16,54 \mathrm{~g}$ Glykogen.

4. Glykogenbestimmung der Eingeweide.

Das Glykogen von $475 \mathrm{~g}$ Eingeweide invertirt in $2000 \mathrm{ccm}$.

Gefunden in $81 \mathrm{ccm}$ Zuckerlösung $=19,24 \mathrm{~g}$ Eingeweide:

1. $472,5 \mathrm{mg} \mathrm{Cu}_{2} \mathrm{O}=215,8 \mathrm{mg}$ Zucker,

2. $472,5 \mathrm{mg} \mathrm{Cu} \mathrm{Cu}_{2} \mathrm{O}$.

$472,5 \mathrm{mg} \quad \mathrm{Cu}_{2} \mathrm{O}=409,5 \mathrm{mg} \quad \mathrm{Cu}=209,6 \mathrm{mg}$ Zucker $=194,3 \mathrm{mg}$ Glykogen.

In den Eingeweiden sind also 1,0895\% Zucker $=1,01 \%$ Glykogen.

$1057 \mathrm{~g}$ Eingeweide enthalten demnach 11,517 g Zucker $=10,676 \mathrm{~g}$ Glykogen. 
Ueber den Maximalwerth des Gesammtglykogengehalts von Hunden. 239

5. Glykogenbestimmung des Felles.

a) $615 \mathrm{~g}$ Fell gelöst in $2000 \mathrm{ccm} 15 \% \mathrm{KOH}$.

Das Glykogen von $500 \mathrm{ccm}$ Felllösung $=153,75 \mathrm{~g}$ Fell invertirt in $1000 \mathrm{ecm}$.

In $81 \mathrm{ccm}$ Zuckerlösung $=12,45 \mathrm{~g}$ F'ell gefunden:

$303,5 \mathrm{mg} \mathrm{Cu}_{2}=129,1 \mathrm{mg}$ Zucker.

$303,5 \mathrm{mg} \mathrm{Cu}_{2} \mathrm{O}=262 \mathrm{mg} \mathrm{Cu}=125,1 \mathrm{mg}$ Zucker $=115,97 \mathrm{mg}$ Glykogen.

Im Fell sind also 1,0045 \% Zucker $=0,9312 \%$ Glykogen.

b) $547 \mathrm{~g}$ Fell gelöst in $2000 \mathrm{ccm} 15 \% \mathrm{KOH}$.

Das Glykogen von 500 cem Felllösung $=136,75 \mathrm{~g}$ Fell invertirt in $1000 \mathrm{ccm}$.

Gefunden in $81 \mathrm{cem}$ Felllösung $=11,68 \mathrm{~g}$ Fell :

$260 \mathrm{mg} \mathrm{Cu}_{2} \mathrm{O}=109,45 \mathrm{mg}$ Zucker.

$260 \mathrm{mg} \mathrm{Cu}_{2} \mathrm{O}=228,8 \mathrm{mg} \mathrm{Cu}=108,4 \mathrm{mg}$ Zucker $=100,49 \mathrm{mg}$ Glykogen.

Im Fell sind $0,9697 \%$ Zucker $=0,8989 \%$ Glykogen.

Im Mittel aus beiden Analysen sind also im Fell 0,9871\% Zucker $=0,9151 \%$ Glykogen.

In $1162 \mathrm{~g}$ Fell sind also 8,4949 $\mathrm{g}$ Zucker $=7,8747 \mathrm{~g}$ Glykogen.

6. Glykogenbestimmung des Herzens.

Das Glykogen von $54 \mathrm{~g}$ Herz invertirt in $400 \mathrm{ccm}$.

In $81 \mathrm{ccm}$ Zuckerlösung $=10,94 \mathrm{~g}$ Herz gefunden :

1. $142,7 \mathrm{mg} \mathrm{Cu} 2 \mathrm{O}=57,85 \mathrm{mg}$ Zucker,

2. $141,3 \mathrm{mg} \mathrm{Cu}_{2} \mathrm{O}$.

$142,7 \mathrm{mg} \quad \mathrm{Cu}_{2} \mathrm{O}=127,5 \mathrm{mg} \mathrm{Cu}=58,25 \mathrm{mg}$ Zucker $=53,998 \mathrm{mg}$ Glykogen.

Im Herzen sind also $0,5328 \%$ Zucker $=04939 \%$ Glykogen. $54 \mathrm{~g}$ Herz enthalten $0,2877 \mathrm{~g}$ Zucker $=0,2667 \mathrm{~g}$ Glykogen.

7. Glykogenbestimmung des Gehirns.

Das Glykogen von $73 \mathrm{~g}$ Gehirn invertirt in $300 \mathrm{cem}$.

Gefunden in $81 \mathrm{ccm}$ Zuckerlösung $=19,7 \mathrm{~g}$ Gehirn :

1. $144 \mathrm{mg} \mathrm{Cu} \mathrm{Cu}_{2}=58,37 \mathrm{mg}$ Zucker,

2. $143,7 \mathrm{mg} \mathrm{Cu}_{2} \mathrm{O}$.

$144 \mathrm{mg} \mathrm{Cu} \mathrm{Cu}_{2} \mathrm{O}=119,2 \mathrm{mg} \mathrm{Cu}=54,1 \mathrm{mg}$ Zucker $=50,2 \mathrm{mg}$ Glykogen.

Im Gehirn" sind also 0,274\% Zucker $=0,254 \%$ Glykogen.

E. Pflüger, Archiv für Physiologie. Bd. 99. 
$73 \mathrm{~g}$ Gehirn enthalten demnach $0,2004 \mathrm{~g}$ Zucker $=0,1858 \mathrm{~g}$ Glykogen.

$$
\text { Versueh VII. }
$$

\begin{tabular}{|c|c|c|c|c|c|}
\hline Gewich & des & Hundes & & . . & $7500 \mathrm{~g}$ \\
\hline$n$ & $n$ & darmreinen Hundes & . & - . & $7452 "$ \\
\hline$n$ & & Blutes. . . & . & . & 393 \\
\hline$\eta$ & der & Leber & . & . . & 380 \\
\hline$n$ & des & . . . & . & . & $939 n$ \\
\hline$n$ & der & Eingewride mit Inhal & & . . & 904, \\
\hline$"$ & $n$ & ohne & & . & $856 "$ \\
\hline 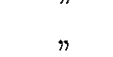 & des & laalben Hundes. & & . & 2508 \\
\hline$"$ & der & auderen Hälfte . & . & . & 2400 \\
\hline$"$ & des & Gehirns . . & . & $\cdot$ & 63 \\
\hline$n$ & $n$ & Herzens . . . & . & . . & 48 \\
\hline$"$ & der & $\begin{array}{l}\text { Muskulatur des halbe } \\
\text { Knochen des halben }\end{array}$ & & $\begin{array}{l}\text { Hundes } \\
\text { ades . }\end{array}$ & $\begin{array}{r}1347 \\
1124\end{array}$ \\
\hline
\end{tabular}

1. Glykogenbestimmung der Leber.

Das Glykogen von $25 \mathrm{~g}$ Leber invertirt in $1000 \mathrm{ccm}$.

Gefunden in $81 \mathrm{ccm}$ Zuckerlösung $=2,025 \mathrm{~g}$ Leber:

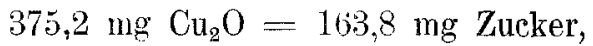
$375,0 \mathrm{mg} \mathrm{Cu}_{2} \mathrm{O}$.

$375,2 \mathrm{mg} \mathrm{Cu} \mathrm{Cu}_{2} \mathrm{O}=325,4 \mathrm{mg} \mathrm{Cu}=159,4 \mathrm{mg}$ Zucker $=147,1 \mathrm{mg}$ Glykogen.

In der Leber sind also 7,8716\% Zucker $=7,297 \%$ Glykogen.

$386 \mathrm{~g}$ Leber enthalten demnach $29,76 \mathrm{~g}$ Zucker $=27,73 \mathrm{~g}$ Glykogen.

2. Glykogenbestimmung der Muskeln.

Das Glykogen von $50 \mathrm{~g}$. Muskel invertirt in $500 \mathrm{ccm}$.

Gefunden in 81 cem Zuckerlösung $=8,1 \mathrm{~g}$ Muskel :

1. $162,2 \mathrm{mg} \mathrm{Cu}_{2} \mathrm{O}=60,3 \mathrm{mg}$ Zucker,

2. $158,0 \mathrm{mg} \mathrm{Cu}_{2} \mathrm{O}$.

$162,2 \mathrm{mg} \mathrm{Cu}_{2} \mathrm{O}=144,3 \mathrm{mg} \mathrm{Cu}=66,4 \mathrm{mg}$ Zucker $=61,6 \mathrm{mg}$ Glykogen.

Im Muskel sind also $0,8198 \%$ Zucker $=0,7599 \%$ Glykogen. $2694 \mathrm{~g}$ Muskeln enthalten demnach 21,63 g Zucker $=20,47 \mathrm{~g}$ Glykogen. 
Ueber den Maximalwerth des Gesammtglykogengehalts von Hunden. 241

3. Glykogenbestimmung der Knochen.

$1124 \mathrm{~g}$ Knochen gelöst in $3200 \mathrm{ccm} 15 \% \mathrm{KOH}$. Das Glykogen von $500 \mathrm{cem} \mathrm{Knochenlösung}=175,62 \mathrm{~g}$ Knochen invertirt in $1000 \mathrm{cem}$.

Gefunden in 81 ccm Zuckerlösung $=14,23 \mathrm{~g}$ Knochen:

1. $108,0 \mathrm{mg} \mathrm{Cu}_{2} \mathrm{O}=42,65 \mathrm{mg}$ Zucker,

2. $107,8 \mathrm{mg} \mathrm{Cu}_{2} \mathrm{O}$.

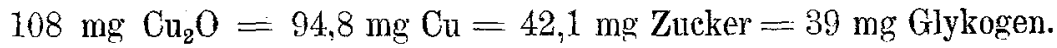

In den Kuochen sind also 0,2952\% Zucker $=0,2736 \%$ Glykogeu

$2248 \mathrm{~g}$ Knochen enthalten demnach $6,63 \mathrm{~g}$ Zucker $=6,15 \mathrm{~g}$ Glykogen.

4. Glykogenbestimmung der Eingeweide.

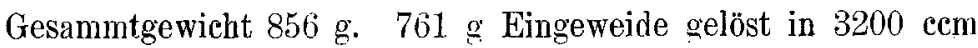
$15 \% \mathrm{KOH}$. Das Glykogen aus $500 \mathrm{ccm}$ Eingeweidelösung invertirt in $600 \mathrm{ccm}$.

Gefunden in $81 \mathrm{ccm}$ Zuckerlösung $=16,05 \mathrm{~g}$ Eingeweide:

1. $91,5 \mathrm{mg} \mathrm{Cu}_{2} \mathrm{O}=35,5 \mathrm{mg}$ Zucker,

2. $91,0 \mathrm{mg} \mathrm{Cu}_{2} \mathrm{O}$.

$91,5 \mathrm{mg} \mathrm{Cu}_{2} \mathrm{O}=80,5 \mathrm{mg} \mathrm{Cu}($ Volhard $)=35,05 \mathrm{mg}$ Zucker $=$ $32,49 \mathrm{mg}$ Glykogen.

In den Eingeweiden sind also 0,2183\% Zucker $=0,2024 \%$ Glykogen.

$856 \mathrm{~g}$ Eingeweide enthalten demnach $1,8868 \mathrm{~g}$ Zucker $=1,7324 \mathrm{~g}$ Glykogen.

5. Glykogenbestimmung des Fells.

$939 \mathrm{~g}$ Fell gelöst in $4000 \mathrm{ccm} 15 \% \mathrm{KOH}$. Das Glykogen von $500 \mathrm{ccm}=117,38 \mathrm{~g}$ Fell invertirt in $750 \mathrm{ccm}$.

Gefunden in $81 \mathrm{ccm}$ Zuckerlösung $==12,68 \mathrm{~g}$ Fell:

1. $40 \mathrm{mg} \mathrm{Cu}_{2} \mathrm{O}=13,35 \mathrm{mg}$ Zucker,

2. $40 \mathrm{mg} \mathrm{Cu}_{2} \mathrm{O}$.

$40 \mathrm{mg} \mathrm{Cu}_{2} \mathrm{O}=36,3 \mathrm{mg} \mathrm{Cu}=11,75 \mathrm{mg}$ Zucker $=10,91 \mathrm{mg}$ Glykog'en.

Im Fell sind also 0,0927\% Zucker $=0,0854 \%$ Glykogen.

$939 \mathrm{~g}$ Fell enthalten demnach $0,8704 \mathrm{~g}$ Zucker $=0,8069 \mathrm{~g}$ Glykogen.

6. Glykogenbestimmung des Herzens.

Das Glykogen von $48 \mathrm{~g}$ Herz invertrt in $300 \mathrm{ccm}$.

Gefunden in 81 eem Zuckerlösung $=12,96 \mathrm{~g}$ Herz: 
1. $89,5 \mathrm{mg} \mathrm{Cu}_{2} \mathrm{O}=34,6 \mathrm{mg}$ Zucker,

2. $89,4 \mathrm{mg} \mathrm{Cu}_{2} \mathrm{O}$.

$89,5 \mathrm{ing} \mathrm{Cu}_{2} \mathrm{O}=79,8 \mathrm{mg} \mathrm{Cu}$ (Volhard) $=34,7$ mg Zucker $=$ $32,2 \mathrm{mg}$ Glykogen.

Im Herzen sind also 0,252\% Zucker $=0,231 \%$ Glykogen. $48 \mathrm{~g}$ Herz enthalten demnach $0,121 \mathrm{~g}$ Zucker $=0,111 \mathrm{~g}$ Glykogen.

7. Glykogenbestimmung des Gehirns.

Das Glykogen von 63 \& Gehirn in $400 \mathrm{ccm}$ invertirt.

Gefunden in $81 \mathrm{ccm}$ Zuckerlösung $=12,70 \mathrm{~g}$ Gehirn:

1. $74,8 \mathrm{mg} \mathrm{Cu}_{2} \mathrm{O}=28,15 \mathrm{mg}$ Zucker,

2. $74,3 \mathrm{mg} \mathrm{Cu}_{2} \mathrm{O}$.

$74,8 \mathrm{mg} \quad \mathrm{Cu}_{2} \mathrm{O}=64,9 \mathrm{mg} \quad \mathrm{Cl}=27,35 \mathrm{mg}$ Zucker $\quad 25,35 \mathrm{mg}$ Glykogen.

Im Gehirn sind also 0,2143\% Zucker $=0,1984 \%$ Glykogen.

$63 \mathrm{~g}$ Gehirn enthalten dennach $0,135 \mathrm{~g}$ Zueker $=0,125 \mathrm{~g}$ Glykogen. 